\title{
Modified auxiliary exergy costing in advanced exergoeconomic analysis applied to a hybrid solar-biomass organic Rankine cycle plant
}

\author{
Joseph Oyekale ${ }^{a, b^{*}}$, Mario Petrollese ${ }^{a}$, Giorgio Cau ${ }^{a}$ \\ ${ }^{a}$ Department of Mechanical, Chemical and Materials Engineering, University of Cagliari, Via Marengo \\ 2, 09123 Cagliari, Italy \\ ${ }^{b}$ Department of Mechanical Engineering, Federal University of Petroleum Resources, Effurun, P.M.B. \\ 1221 Effurun, Delta State, Nigeria \\ *Corresponding author: oyekale.oyetola@fupre.edu.ng
}

\begin{abstract}
:
This study concerns advanced exergoeconomic analysis of a hybrid solar-biomass organic Rankine cycle (ORC) cogeneration plant. The hybrid plant had been previously conceived as structural optimization scheme to upgrade thermo-economic performance of a real $630 \mathrm{~kW}$ solar-ORC plant which currently runs in Ottana, Italy. The irreversibility rates, investment cost rates and irreversibility cost rates were obtained for each system component, based on thermodynamic balance as well as cost balance and auxiliary equations established for the components. Next, the avoidable/unavoidable and exogenous/endogenous splitting options were applied to investigate the sources of thermo-economic losses in the system, the effects of component interactions on the losses, as well as the best approach to improving the system. The main contribution of this paper centers on modification of the traditional auxiliary exergy costing in advanced exergoeconomic methodology, by incorporating stream energy quality into the cost formation process. Results showed that more than $50 \%$ of total irreversibility rates can be avoided in almost all of the components of the hybrid plant, most of which are endogenous. Similarly, it was obtained that component interdependencies have little impact on thermo-economic losses. Specifically, more than $60 \%$ of irreversibility cost rates could be avoidable in the hybrid plant by optimizing internal operations of each of the system components individually. Moreover, results showed that how auxiliary exergy costing is defined in advanced exergoeconomic method plays a significant role on the analysis, and the modified approach presented in this study is a viable choice.
\end{abstract}

\section{Keywords:}

${ }^{1}$ Organic Rankine Cycle; Hybrid solar-biomass energy; Advanced exergy analysis; Advanced exergoeconomic analysis; Auxiliary exergy costing

\footnotetext{
${ }^{1}$ The short version of the paper was presented at ICAE2019, Aug 12-15, Västerås, Sweden. This paper is a substantial extension of the short version of the conference paper.
} 


\section{Introduction}

Solar irradiation is one renewable energy resource that is freely available to all, and this has attracted global attention to its potential exploitation for production of thermal and electrical energy. In fact, practical implementations of solar-based systems are growing rapidly nowadays [1], a scenario that could be justified in two ways. First, the world population is increasing, and so is the demand for primary energy [2]. Second, fossil fuels which currently dominate the world energy mix are not sustainable, due to their unhealthy impacts on the environment as well as their propensity to get depleted someday. However, exploitation of solar energy is equally characterised with a number of challenges, as is common with many renewable energy resources. Prominent amongst these are low technical efficiency of solar-based energy conversion systems, high cost of power production, as well as low system reliability. The major reason attributable to this is the high dependence of solar irradiation on weather conditions, which fluctuate in reality. Thus, coordinated efforts are required to ameliorate these challenges, for improved performance of solar energy systems. In particular for concentrated solar power (CSP) plants which are the preferred solar technologies for production of thermal power directly from solar irradiation, one of such improvement efforts is based on systemic optimization of structural designs, basically by integrating thermal energy storage (TES) systems and by hybridizing other energy sources [3]. In this regard, several studies have proposed measures to hybridize CSP systems with other renewable energy resources, with emphasis on the more dispatchable ones such as biomass [4]. This sometimes includes enhancement of power conversion processes, by paying special attention to upgrading turbomachines [5]. However, such structural improvements usually expand the nature of interactions amongst system components with consequent increase in thermo-economic losses. Thus, methods capable of revealing quantity and sources of technical and economic losses in structurally-optimized solarbased systems are quite relevant for scientific investigations, as they can further stimulate improvement of such systems.

Generally, such methods are based on the second law of thermodynamics, commonly referred to as exergy analysis [6]. Exergy analysis tracks the quality of different forms of energy transiting the boundary of a thermodynamic system [7], and it takes due account of internal losses in system components or processes [8]. The concept has equally been extended to thermo-economic assessment of thermodynamic systems [9], in an approach generally known today as exergoeconomic [10] or exergy cost [11] analysis. Exergoeconomic analysis integrates economic principles with exergy concepts, to define flow of investment and operational costs in a thermodynamic system, as well as to investigate economic devaluations and their locations [12]. In this regard, the specific exergy cost (SPECO) approach [13], the exergy cost theory [14] and other exergoeconomic approaches have been developed. The methodology has been adjudged quite essential for assessing optimization potentials in modern energy systems [15], and studies abound in the open literature on its applications [16]. At the moment, some of its weaknesses and possible ways of improvement are being discussed, which has led to different modifications, the most recent of which has been given the nomenclature advanced exergoeconomic analysis [17]. Beyond what is possible in the conventional exergoeconomic method, advanced analysis enables characterisation of losses in a component due to its interactions with other components, as well as the actual lost exergy and associated costs that could be avoidable by optimization efforts [18].

The quantity and quality of research studies involving advanced exergoeconomic methodology is a case in point to justify its relevance and wide acceptance . Mehrpooya and Mousavi [19] carried out an advanced exergoeconomic evaluation of a solar-driven Kalina cycle plant, to assess exergy costs lost in different components due to their individual operations as well as global interactions at system level. They identified absorber and pump to respectively have the highest and lowest cost rates of destroyed exergy in the system. Yu, Cui, Wang, Liu, Zhu, and Yang [20] compared conventional and advanced exergoeconomic analysis for the assessment of a cascade absorption refrigeration system driven by low-grade waste heat. They analysed in detail, the similarities and differences of the results obtained from the two methods, and concluded that advanced 
exergoeconomic analysis gives better understanding of optimization potentials in the system. Liu, Liu, Yang, Zhai, and Yang [21] presented a comprehensive advanced exergoeconomic analysis of a 10 MW supercritical Brayton cycle plant running on carbon dioxide and integrated with energy storage device. The analysis identified expander as the component with the highest potential for system improvement, an information that was reportedly suppressed when conventional exergoeconomic method was applied to the same system. Wang, Liu, Liu, Zhang, Cui, Yu et al. [22] evaluated a cascade absorption heat transformer for recovery of waste heat, using both conventional and advanced exergoeconomic methods. They reported that results obtained from the two methods are not consistent, and based on the advanced method, about $20 \%$ of destroyed exergy could be avoided, while about $80 \%$ of the investment cost rates were found to be from the components themselves. Ansarinasab, Mehrpooya, and Mohammadi [23] applied advanced exergoeconomic method to assess a hydrogen liquefaction plant, in order to investigate the potentials for system improvement. Results showed that interaction of system component has very little effects on thermoeconomic losses. The authors however reported that only a small fraction of destroyed exergy in the system could be generally avoided in reality. Similarly, Anvari, Khoshbakhti Saray, and Bahlouli [24] applied conventional and advanced exergoeconomic analysis to identify components with high improvement potentials in a tri-generation system producing heat, cold and power. Like other aforementioned studies, they equally underscored the more comprehensiveness of the advanced methodology relative to the conventional one. They reported that about $29 \%$ of the irreversibility and irreversibility cost rates are due to internal operations of each system components, excluding their interrelations, all of which could be avoided technically. Dai, Zhu, Wang, Sun, and Liu [25] applied advanced exergoeconomic method to evaluate different hydrocarbons as working fluids in organic Rankine cycle (ORC) plant, considering different renewable thermal energy sources. They ranked improvement potentials in ORC components as expander, evaporator, condenser and pump, in descending order. Also, they demonstrated that advanced exergoeconomic analysis could be applied to study sensitivity of heat source temperature to thermo-economic performance of different ORC working fluids. Kacebas and Hepbasli [26] analysed a real geothermal district heating system operating in Afyonkarahisar, Turkey using conventional and advanced exergoeconomic analyses. They reported that, beyond the conventional method, advanced exergoeconomic analysis enabled the realization of the fact that substantial system cost rates lost in the plant operation are due to internal designs, and could be avoided. In another similar study, Kacebas, Gökgedik, Alkan and Kecebas [27] employed advanced exergoeconomic analysis to compare two geothermal district heating systems, where the usefulness and importance of this method was further demonstrated. The study is based on operational systems, and the one deserving of more optimization was readily identified with the aid of the advanced exergoeconomic method. Also, Vuckovic, Stojiljković, Vukić, Stefanović, and Dedeić [28] employed advanced exergoeconomic method to evaluate optimization potentials in an industrial polygeneration energy plant used for producing steam, compressed air, cooling water and sanitary hot water in a rubber factory. It was reported that the energy plant was practically optimized by implementing the findings of the advanced exergoeconomic analysis. Boyaghchi and Sabaghian [29] evaluated a Kalina cycle plant driven by parabolic trough solar collectors. High exergy and exergy cost losses were discovered to be due to system interactions, with possibilities of avoiding about $84 \%$ of the investment and irreversibility cost rates.

All the above-cited papers have clearly demonstrated the viability and versatility of the advanced exergoeconomic methodology for analysis of thermodynamic systems. Nevertheless, it could be deduced from literature review that application to solar-based systems are somewhat scanty, which makes the current study relevant, in the authors' opinion, in terms of knowledge contribution to this field. In addition, a traditional way was identified from the literature review reported above, for assigning unit auxiliary cost of exergy in advanced exergoeconomic method. This traditional approach assumes that the unit cost of exergy entering and leaving a system component is constant, irrespective of the quality of energy in the different streams. However, it has been sufficed previously that quality of stream energy should be taken into account while assigning exergy cost 
[30], which has not yet been incorporated into the advanced exergoeconomic analysis, to the best of the authors' knowledge. Thus, a modified approach of auxiliary exergy costing which incorporates energy quality level of different streams is considered for the first time in advanced exergoeconomic analysis in this study. In particular, comparative advanced exergoeconomic analysis is applied to a conceptual hybrid solar-biomass ORC cogeneration plant [31], based on both the aforementioned traditional and modified auxiliary exergy costing approaches. The tangential objectives of this paper are:

- To quantify the potentials of reducing irreversibility in the hybrid plant components due to their individual operations as well as due to their structural interdependencies;

- To quantify the potentials of improving investment and irreversibility cost rates in the hybrid plant components due to their individual operations as well as due to their structural interdependencies;

- To comparatively investigate the effects of incorporating stream energy quality to auxiliary exergy costing in advanced exergoeconomic analysis based on the studied hybrid solarbiomass plant.

The details of the methods applied are reported in section 2 of this paper, while the results are highlighted and discussed in section 3. The main findings are summarised in section 4.

\section{Methodology}

\subsection{System description}

Figure 1 shows the conceptual hybrid Concentrated Solar Power (CSP)-biomass Organic Rankine Cycle (ORC) plant studied in this paper [32]. As illustrated, it is possible for the ORC to be fed by thermal power from either or both of the solar field and biomass furnace, depending on availability. The solar field integrates Linear Fresnel Collectors (LFC) with a two-tank Thermal Energy Storage (TES) system, as can be seen in Figure 1. Thermal oil is used as heat transfer fluid (HTF) and storage medium in the solar field and TES, respectively. TES hot tank stores the useful thermal energy produced by the solar collectors, and it feeds the ORC directly. A modular combustion furnace is considered in the biomass section, having a distinct combustion zone where biomass fuels are burnt, as well as a small boiler where hot combustion gases heat up the HTF to be fed directly into the ORC. The same HTF is considered in the solar-field/TES and the biomass sections, and its flow into the ORC is regulated by a three-way valve upstream of the ORC. A second threeway valve controls the flow of HTF exiting the ORC unit, for distribution into the TES cold tank and the cold side of the biomass boiler. Then, the cold HTF in the TES tank flows through the solar field for heat addition, while the portion in the biomass boiler is heated by hot combustion gases, and the cycle continues. Inlet air into the combustion zone of the biomass furnace is pre-heated by hot combustion flue gases exiting the furnace heater. The ORC is of recuperative subcritical configuration, with hexamethyldisiloxane $(M M)$ as working fluid and water as heat sink. Design characteristics of the hybrid plant are highlighted in Table 1. As aforementioned, this study seeks to modify cost formation process in advanced exergoeconomic analysis, with reference to the real ORC plant. Suffice it to emphasise here that the details of components design, modelling and firstlaw-based techno-economic analysis of the hybrid plant have been reported in a previous study, which also includes validation of simulation results with experimental data obtained from the real plant [32]. Based on this previous study, it is assumed here that biomass furnace constantly satisfies $40 \%$ of the required ORC nominal thermal input, which corresponds to the minimum power essential for continuous plant operation. The types and sizes of components analysed in this paper are as contained in the real plant, and detailed design and selection criteria are thus not repeated. 


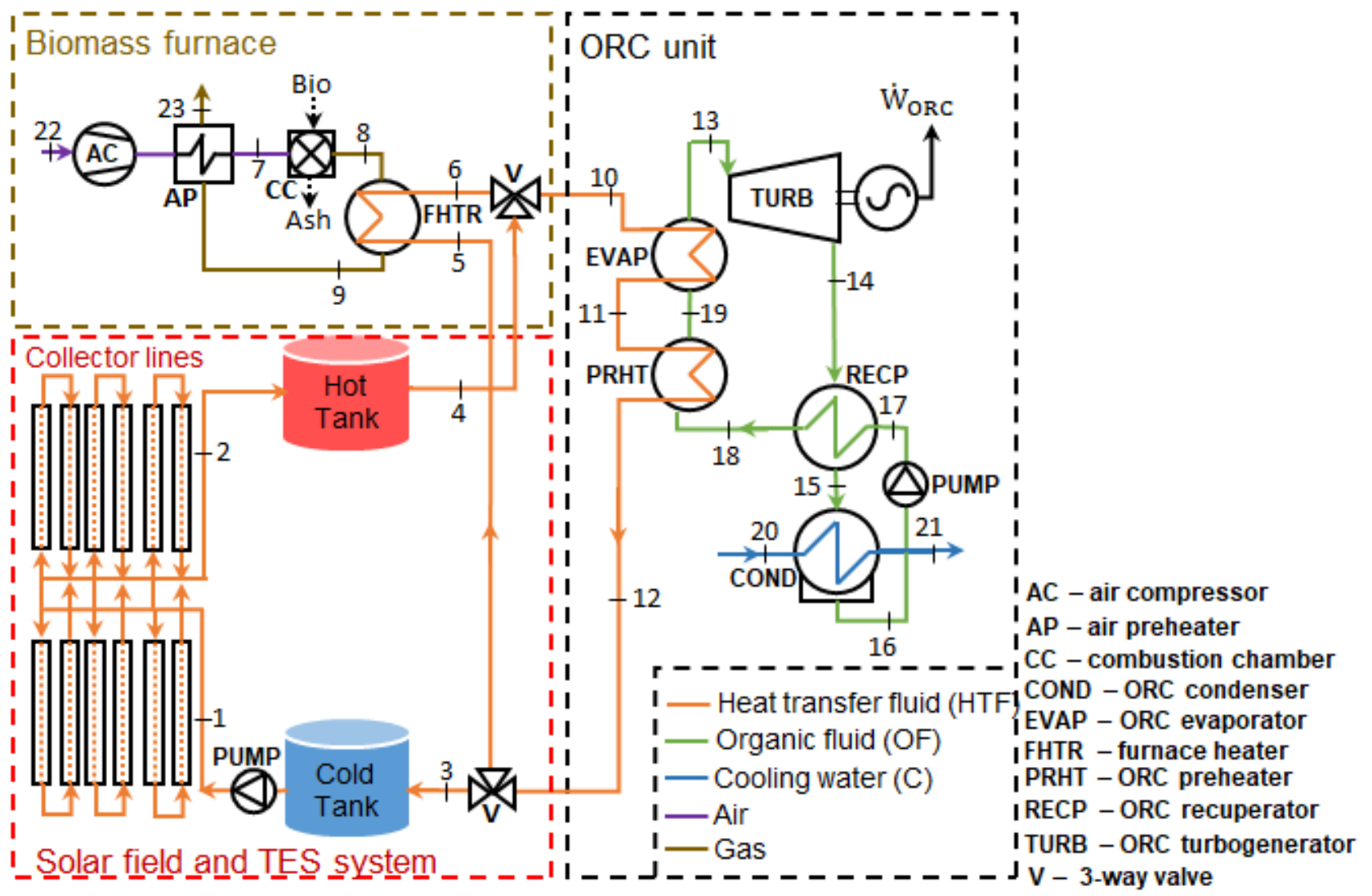

Figure 1 - Conceptual scheme of the hybrid CSP-biomass ORC plant [32]

Table 1 - Design characteristics of hybrid CSP-biomass ORC plant

\begin{tabular}{|c|c|c|c|}
\hline \multicolumn{2}{|l|}{ Solar Field } & \multicolumn{2}{|l|}{ ORC unit } \\
\hline Collector focal length & $4.97 \mathrm{~m}$ & Working fluid & $\mathrm{C}_{6} \mathrm{H}_{18} \mathrm{OSi}_{2}$ \\
\hline Collector length & $99.45 \mathrm{~m}$ & Heat sink & Water \\
\hline Net effective area $\left(\mathrm{A}_{\mathrm{sf}}\right)$ & $8400 \mathrm{~m}^{2}$ & Net electrical power & $629 \mathrm{~kW}$ \\
\hline Optical efficiency $\left(\eta_{O P T}^{d}\right)$ & $64 \%$ & Design thermal power input & 3178 kW \\
\hline Mean ambient temperature & $25^{\circ} \mathrm{C}$ & Design HTF mass flow rate & $11.05 \mathrm{~kg} / \mathrm{s}$ \\
\hline Mean ambient pressure & $1 \mathrm{~atm}$ & Pump isentropic efficiency & $80 \%$ \\
\hline Design inlet temperature & $165^{\circ} \mathrm{C}$ & Pump motor efficiency & $98 \%$ \\
\hline Design outlet temperature & $275^{\circ} \mathrm{C}$ & $\begin{array}{l}\text { Turbine isentropic efficiency } \\
\text { Electromechanical efficiency }\end{array}$ & $\begin{array}{l}85 \% \\
92 \%\end{array}$ \\
\hline \multicolumn{2}{|l|}{ TES system } & \multicolumn{2}{|l|}{ Biomass Combustion } \\
\hline Storage capacity & 15.4 MWh & Furnace thermal duty & $1430 \mathrm{~kW}$ \\
\hline Tank useful volume & $330 \mathrm{~m}^{3}$ & \multirow{3}{*}{$\begin{array}{l}\text { Fuel composition (dry basis, } \\
\% \text { by weight) }\end{array}$} & $48.3 \% \mathrm{C}, 5.9 \% \mathrm{H}$, \\
\hline Aspect ratio & 0.32 & & $0.1 \% \mathrm{~N}_{2}, 38.5 \%$ \\
\hline Ambient wind speed $\left(v_{a}\right)$ & $3 \mathrm{~m} / \mathrm{s}$ & & $\mathrm{O}_{2}, 7.2 \%$ Ash \\
\hline Insulation thickness & $0.5 \mathrm{~m}$ & LHV (dry basis) & $16.3 \mathrm{MJ} / \mathrm{kg}$ \\
\hline \multirow{4}{*}{$\begin{array}{l}\text { Insulation thermal } \\
\text { conductivity }\end{array}$} & \multirow{4}{*}{$0.16 \mathrm{~W} / \mathrm{m}^{2} \mathrm{~K}$} & Moisture content & $20 \%$ \\
\hline & & Stoichiometric air-fuel ratio & 5 \\
\hline & & Excess air & $150 \%$ \\
\hline & & Combustion efficiency & $99 \%$ \\
\hline
\end{tabular}

\subsection{Thermodynamic analysis}

Application of advanced exergoeconomic methodology to the study of energy systems requires prior analysis based on advanced exergy approach. This in turn entails establishment of mass and energy balances in each system component, based on both first and second laws of 
thermodynamics. Thus, the classical mass, energy and exergy balance equations were first applied to each component of the hybrid plant under study, as follows [33]:

$$
\begin{gathered}
\sum \dot{\mathrm{m}}_{i}=\sum \dot{\mathrm{m}}_{\mathrm{o}} \\
\sum \dot{\mathrm{m}}_{\mathrm{i}} \mathrm{h}_{\mathrm{i}}+\dot{\mathrm{Q}}=\sum \dot{\mathrm{m}}_{\mathrm{o}} \mathrm{h}_{\mathrm{o}}+\dot{\mathrm{W}} \\
\sum \dot{\mathrm{m}}_{\mathrm{i}} \mathrm{e}_{\mathrm{i}}+\dot{\mathrm{Q}}\left(1-\frac{T_{a}}{T_{c}}\right)=\sum \dot{\mathrm{m}}_{\mathrm{o}} \mathrm{e}_{\mathrm{o}}+\dot{\mathrm{W}}+\dot{\mathrm{I}}
\end{gathered}
$$

where $\dot{m}$ is the mass flow rate of the stream substance, $h$ the specific enthalpy, $\dot{Q}$ the heat flow through component boundary, $T_{a}$ the temperature of the environment, $T_{c}$ the temperature at component boundary, $e$ the specific exergy of the stream, $\dot{W}$ the work rate, and $\dot{I}$ the rate of exergy destroyed in the component (irreversibility). Subscripts $i$ and $o$ represent inlet and exit to and from the component, respectively. For defining $e$, Kotas [7] expressed that physical and chemical exergy components are usually sufficient in most applications, since kinetic and potential components are often infinitesimally small or equivalent in all streams, and can thus be neglected. Also, in processes with no chemical reactions taking place or where chemical exergy cancels out between two adjoining thermodynamic states, only physical exergy is necessary to estimate $e$, expressed fundamentally as:

$$
e_{p h}=\left(h-h_{a}\right)-T_{a}\left(s-s_{a}\right)
$$

where $s$ is the stream specific entropy, with subscript $a$ denoting properties of the environment. Specific chemical exergy of a stream is a function of its composition and reference state of the environment. In this study, specific chemical exergy $\left(e_{c h}\right)$ of flue gases was computed as:

$$
e_{c h}=\left(\sum_{i} x_{i} \hat{\mathrm{r}}_{i}+\mathrm{R} T_{a} \sum_{i} x_{i} \ln x_{i}\right) / m m
$$

where $x_{i}$ and $\hat{\mathrm{r}}_{i}$ represent molar fraction and reference standard exergy of each component of the gaseous streams (obtained from [33]), respectively; $R$ is the universal gas constant, and $m m$ the average molar mass of the chemical stream. For the biomass fuel, the expression given in [7] for specific chemical exergy $\left(e_{c h, b}\right)$ was adopted, as follows:

$$
e_{c h, b}=\beta \cdot L H V
$$

where $L H V$ is the lower heating value of the biomass fuel, and $\beta$ the index that quantifies chemical exergy in organic fuels, expressed as follows [7]:

$$
\beta=\frac{1.044+0.016 \frac{H}{C}-0.34493 \frac{O}{C}\left(1+0.0531 \frac{H}{C}\right)}{1-0.4124 \frac{O}{C}}
$$

Based on the composition of the biomass fuel assumed in this study (Sardinian Eucalyptus, given in Table 1), $\beta$ was obtained as 1.141.

Furthermore, conventional exergetic efficiency was computed for each system component $j$, as follows: 


$$
\varepsilon_{j}=\frac{\dot{E}_{o, j}}{\dot{E}_{i, j}}
$$

where $\dot{E}_{o, j}$ is the product exergy (output) of component $j$, and $\dot{E}_{i, j}$ the fuel exergy (input). This required adequate definition of productive structure for each component of the hybrid solar-biomass cogeneration plant, as shown in Figure 2. In the figure, CC stands for combustion chamber, AP for air preheater, FH for furnace heater, SF for solar field, CT for TES cold tank, HT for hot tank, V for three-way valve, and PRHT, EVAP, RECP COND and TURB for ORC preheater, evaporator, recuperator, condenser and turbine, respectively. Also, subscripts in exergy terms correspond to the system thermodynamic states as defined in Figure 1.

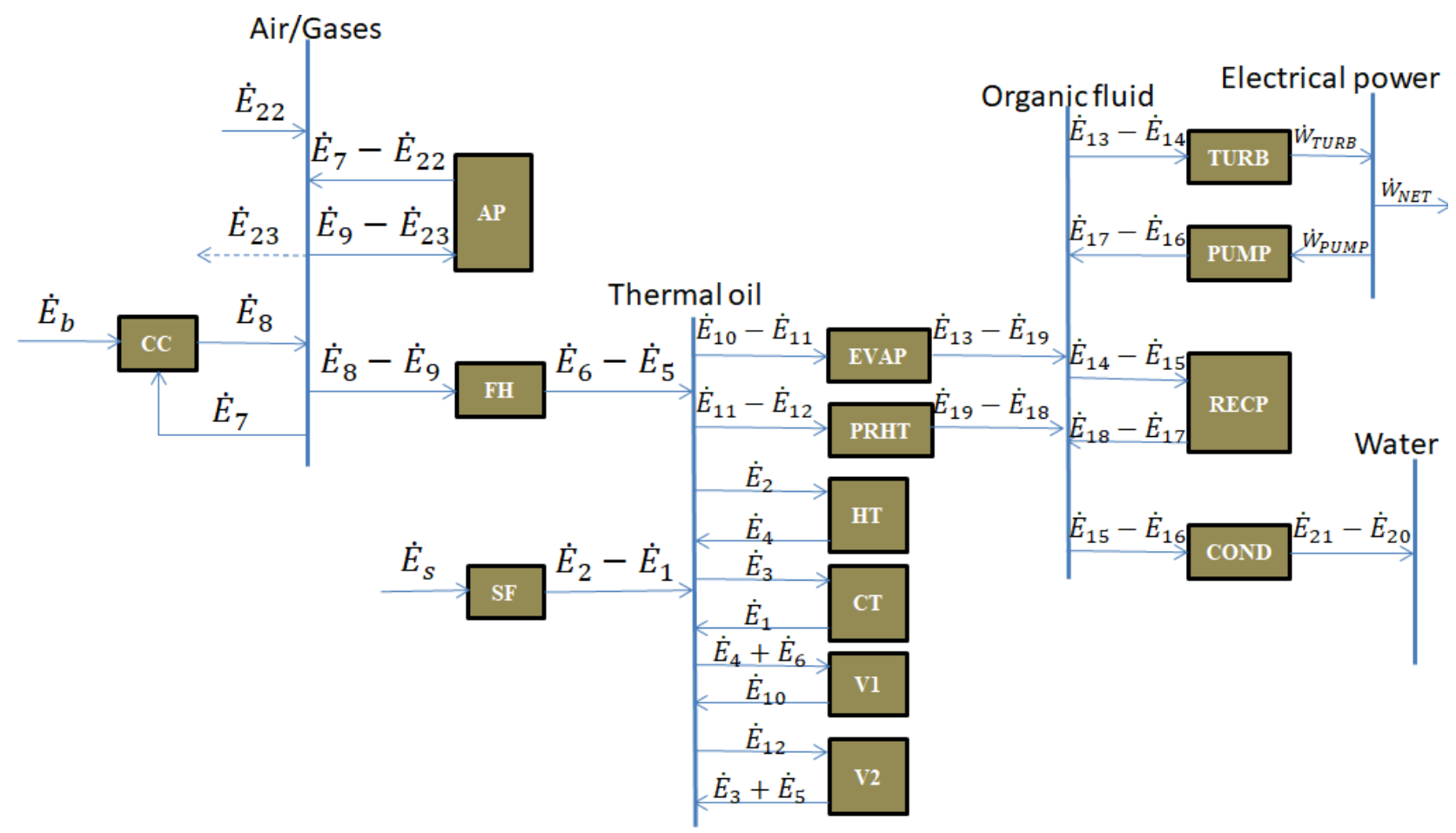

Figure 2 - Productive structure of the hybrid solar-biomass plant

For the exergy of solar irradiation which is the "fuel" for the solar field, the definition proposed in [34] was adopted, as follows:

$$
\dot{E}_{s}=D N I \cdot A_{s f}\left[1-\frac{4}{3} \frac{T_{a}}{T_{s}}+\frac{1}{3} \frac{T_{a}^{4}}{T_{s}^{4}}\right]
$$

where $D N I$ is the direct normal irradiation, $A_{s f}$ the total area of solar collectors and $T_{s}$ the temperature of the sun (taken as $5770 \mathrm{~K}$ ). All other fuel and product exergy represented in Figure 2 were obtained by applying the mass, energy and exergy balance equations to the hybrid plant, as mentioned earlier.

\subsection{Advanced exergy analysis}

By applying the exergy balance equation (Eq. 3) to the system, it is possible to quantify irreversibility in each component, which is a major goal in conventional exergy analysis of thermodynamic systems. However, this information is somewhat limited in applicability to improving design and operation of real energy systems, since some part of such irreversibilities might be unavoidable due to technical constraints of the system. Also, some parts of irreversibility in a system component might be as a result of operations and imperfections in other system 
components. Thus, the advanced exergy methodology had been proposed [35], which for each system component $j$, aims to quantify separately the avoidable and unavoidable parts of irreversibility, as well as to identify irreversibility parts that are due to operation of the component $j$ itself (endogenous) and those due to its interaction with other components (exogenous). In essence, advanced exergy methodology involves analysis of systems under three different conditions: real thermodynamic conditions, unavoidable conditions (for splitting irreversibility into avoidable and unavoidable parts) and theoretical conditions (for splitting irreversibility into endogenous and exogenous parts) [36].

In order to separate irreversibility in a component $j$ to unavoidable $\left(\dot{I}^{\text {un }}\right)$ and avoidable $\left(I^{a v}\right)$ parts, thermodynamic assumptions are made that guarantees its operation at extremely efficient conditions, requiring infinite investment cost. When the assumed conditions are applied to component $j$ while other components work at their real thermodynamic conditions, a hybrid system is created, and the ratio of irreversibility to product exergy in component $j$ under this condition, $\left(\frac{\dot{\mathrm{I}}}{\dot{\mathrm{E}}_{o}}\right)_{j}^{u n}$, is obtained. Then, the unavoidable irreversibility in component $j$ is obtained as:

$$
\dot{I}_{j}^{u n}=\dot{E}_{o, j} \times\left(\frac{\dot{\mathrm{I}}}{\dot{\mathrm{E}}_{o}}\right)_{j}^{u n}
$$

This leaves the avoidable part of total irreversibility in component $j\left(\dot{I}_{j}\right)$ to:

$$
\dot{I}_{j}^{a v}=\dot{I}_{j}-\dot{I}_{j}^{u n}
$$

Also, $\dot{I}_{j}$ is separated into endogenous and exogenous parts by creating other sets of hybrid systems. In particular, when all other components of the plant are assumed to operate under theoretical thermodynamic conditions $(\varepsilon=100 \%)$ while component $j$ operates under its real conditions, irreversibility in $j$ excludes effects of its interactions with other components and is termed endogenous irreversibility $\left(\dot{I}_{j}^{e n}\right)$. Then, the exogenous part $\left(\dot{I}_{j}^{e x}\right)$ is obtained as:

$$
\dot{I}_{j}^{e x}=\dot{I}_{j}-\dot{I}_{j}^{e n}
$$

Furthermore, a more comprehensive analysis is obtainable by combining the splitting options, such that $\dot{I}_{j}$ would be divided into unavoidable endogenous $\left(\dot{I}_{j}^{u n, e n}\right)$, avoidable endogenous $\left(\dot{I}_{j}^{a v, e n}\right)$, unavoidable exogenous $\left(\dot{I}_{j}^{u n, e x}\right)$ and avoidable exogenous $\left(\left(\dot{I}_{j}^{a v, e x}\right)\right.$ parts. According to [37], $\dot{I}_{j}^{u n, e n}$ is given as:

$$
\dot{I}_{j}^{u n, e n}=\dot{\mathrm{E}}_{o, j}^{e n} \cdot\left(\frac{\dot{\mathrm{I}}}{\dot{\mathrm{E}}_{o}}\right)_{j}^{u n}
$$

where $\dot{\mathrm{E}}_{o, j}^{e n}$ is the product of component $j$ obtained when all other components operate under theoretical conditions, as aforementioned. Other parts of the combined splitting options are thus given as [37]:

$$
\begin{aligned}
& \dot{I}_{j}^{a v, e n}=\dot{I}_{j}^{e n}-\dot{I}_{j}^{u n, e n} \\
& \dot{I}_{j}^{u n, e x}=\dot{I}_{j}^{u n}-\dot{I}_{j}^{u n, e n}
\end{aligned}
$$




$$
\dot{I}_{j}^{a v, e x}=\dot{I}_{j}^{e x}-\dot{I}_{j}^{u n, e x}
$$

In essence, application of applied exergy analysis requires adequate definition of the assumptions to be adopted for each component under unavoidable and theoretical conditions, depending on component type and the nature of thermodynamic process it facilitates. An overview is summarised in the following sub-sections, for the real conditions under which each unit of the hybrid plant being studied operate, as well as the conditions assumed for the advanced exergy analysis.

\subsubsection{Solar field}

The real thermal power produced by the solar field $\left(\dot{Q}_{S F}\right)$ was calculated as:

$$
\dot{Q}_{S F}=A_{S F} \cdot\left[D N I \cdot \eta_{O P T}^{d} \cdot I A M \cdot \eta_{E N D} \cdot \eta_{C L N}-\left(a_{1}\left(T_{a v}-T_{a}\right)+a_{2}\left(T_{a v}-T_{a}\right)^{2}+\dot{q}_{p l}\right)\right]
$$

where $\eta_{O P T}^{d}$ is the design optical efficiency, IAM the Incidence Angle Modifier (calculated with reference to [38]), $\eta_{E N D}$ the end-loss optical efficiency, $\eta_{C L N}$ the surface cleanliness efficiency, $a_{1}$ and $a_{2}$ the coefficients of receiver thermal losses (imposed equal to $0.056 \mathrm{~W} / \mathrm{m}^{2} \mathrm{~K}$ and $0.213 \cdot 10^{-3}$ $\mathrm{W} / \mathrm{m}^{2} \mathrm{~K}^{2}$ respectively [38]), $T_{a v}$ the mean value of inlet and exit HTF temperatures in the solar field, and $\dot{q}_{p l}$ the piping thermal losses (set equal to $5 \mathrm{~W} / \mathrm{m}^{2}$ ). Average DNI of $501 \mathrm{~W} / \mathrm{m}^{2}$ was used for analysis, in order to maintain energy balance of the solar field based on the imposed fraction of ORC input thermal power it is designed to cover (60\%) post biomass retrofit. Starting with the $\dot{Q}_{S F}$ obtained and by applying the balance equations to the solar field, the real exergy flowing through solar field and TES for input into the power block was obtained. The values of $\eta_{O P T}^{d}$ and $\eta_{C L N}$ used under real conditions are reported in Table 1, while $\eta_{E N D}$ was obtained as a function of solar collector length and focal length, based on [38].

Analysis presented in [39] was adapted for creating the hybrid system needed to determine unavoidable irreversibility in the solar field. For theoretical conditions, it was assumed that no thermal power is lost due to flow of HTF in the solar field and all optical and end losses were also neglected. The exact assumptions made for solar field under unavoidable and theoretical conditions are highlighted in Table 2 and Table 3, respectively.

\subsubsection{Biomass combustion unit}

The biomass combustion unit consists of two sections: the combustion zone where biomass fuel is burnt inside a small furnace, and the heat exchange zone where the hot combustion gases transfer heat to the liquid HTF via a counter-flow shell and tube liquid-gas heat exchanger. Based on the mass and energy balance equations of the combustion zone and by imposing design excess air value (Table 1), mass flow rate and temperature of hot combustion gases exiting the combustion furnace were obtained [40]. Then, mass and energy balance equations were also applied to the heat transfer zone. On one hand, the thermal power to be produced by the biomass combustion unit $\left(\dot{Q}_{B}\right)$ is known, based on the fraction of ORC inlet thermal power it is designed to cover post hybridization (40\%, amounting to about $1271 \mathrm{~kW}$ ). On the other hand, $\dot{\mathrm{Q}}_{\mathrm{B}}$ depends on the energy content of the biomass fuel (reported in Table 1$)$ and the mass flow rate of the biomass fuel $\left(\dot{m}_{B}\right)$, as follows:

$$
\dot{Q}_{B}=\dot{m}_{B} \cdot L H V_{B} \cdot \eta_{f u r}
$$

where $L H V$ is the lower heating value (highlighted in Table 1) and $\eta_{\text {fur }}$ the furnace efficiency due to thermal losses arising from imperfect insulation, etc.

High temperature of hot combustion gases and air-fuel ratio of 1 were assumed to create the hybrid system used for splitting irreversibility of the combustion unit into unavoidable and avoidable parts. Under the theoretical conditions, the excess air values were assumed to be the same as in the real system, pinch point temperature differences of the furnace heater as well as air pre-heater were 
assumed equal to zero and the thermal losses in the combustion furnace were also assumed equal to zero.

\subsubsection{TES system}

As aforementioned and as can be seen in Figure 1, the TES system consists of one hot and one cold tanks, for storing output and inlet HTF flowing from and to the solar field, respectively. Under real conditions, the two tanks were modelled by considering mass contents of the HTF, the variation of which is due to intermittence of its inlet and outlet mass flow rates. Also, the energy content in each tank correlates with the average temperature of the thermal oil stored therein, based on the energy flow through inlet and outlet mass flow rates and the thermal losses due to imperfect insulation of the tank. The thermal losses are in form of temperature drop in the tank, modelled in this study as follows [41]:

$$
\frac{T(t)-T_{a}}{T_{i}-T_{a}}=e^{-\left(U \cdot A_{T E S} \cdot t\right) /\left(\rho_{H T F} \cdot c_{H T F} \cdot V_{H T F}\right)}
$$

where $\rho_{H T F}, V_{H T F}$, and $c_{H T F}$ are the density, volume and specific heat capacity of heat transfer fluid, respectively; $A_{T E S}$ is the heat transfer area of storage thermal oil, $t$ the time, and $U$ the overall heat transfer coefficient, obtained as follows [42]:

$$
U=\frac{d_{\text {ins }}}{k_{\text {ins }}}+\frac{1}{\alpha_{\text {air }}}
$$

where $d_{\text {ins }}(0.5 \mathrm{~m})$ and $k_{\text {ins }}\left(0.16 \mathrm{~W} / \mathrm{m}^{2} \mathrm{~K}\right)$ are respectively the thickness and thermal conductivity of the insulation material. The convection heat transfer coefficient of air $\left(\alpha_{\text {air }}\right)$ was estimated as a function of the wind speed $\left(v_{a}\right)$, as follows:

$$
\alpha_{\text {air }}=10.45-v_{a}+10 \sqrt{v_{a}}
$$

Climatic conditions of Ottana $\left(40^{\circ} 25^{\prime} 00^{\prime}{ }^{\prime} \mathrm{N}, 9^{\circ} 00^{\prime} 00^{\prime \prime} \mathrm{E}\right)$ were adopted for investigation, as obtained from Meteonorm Software [43].

The assumptions of perfect insulation of the TES tanks were made for the analysis of TES unit under the unavoidable and theoretical operating conditions, as highlighted in Tables 2 and 3.

\subsubsection{ORC unit}

The thermodynamic balance equations (1-3) were used to formulate zero-dimensional models for all ORC components under real conditions, with reference to [44]. In particular, thermodynamic imperfections in turbo machines are due to internal and mechanical losses, while those in heat exchangers are functions of heat transfer ineffectiveness based on high pinch point temperature differences. The design characteristics of the ORC system under the real conditions are highlighted in Table 1. Based on the existing ORC plant running at Ottana, inlet and exit temperatures of thermal source HTF were fixed at $275{ }^{\circ} \mathrm{C}$ and $165^{\circ} \mathrm{C}$, respectively. Thermodynamic properties of all streams were obtained from CoolProp [45], and calculations were performed in Matlab environment. Equation of state reported by Thol et al. [46] was employed in CoolProp for computing properties of ORC working fluid $(M M)$. Also, specific heat properties of the source HTF were obtained from CoolProp, based on the commercial datasheets provided by fluid manufacturers [45].

Assumptions made for the analysis of ORC components under the unavoidable and theoretical operating conditions are also reported in Table 2 and Table 3, respectively.

Table 2. Assumptions for unavoidable irreversibility conditions in plant components

\begin{tabular}{llll}
\hline Component & Unavoidable conditions & Component & Unavoidable conditions \\
\hline
\end{tabular}




\begin{tabular}{llll}
\hline Solar field & $\left(\frac{\dot{\mathrm{I}}}{\dot{\mathrm{E}}_{o}}\right)_{s f}^{U N}=0.7638[39]$ & Furnace heater & $\Delta T_{\min }=3 \mathrm{~K}$ \\
Hot tank & Perfect insulation & ORC preheater & $\Delta T_{\min }=3 \mathrm{~K}$ \\
Cold tank & Perfect insulation & Evaporator & $\Delta T_{\min }=5 \mathrm{~K}$ \\
\hline Air preheater & $\Delta T_{\min }=12 \mathrm{~K}$ & Recuperator & effectiveness $=0.9$ \\
& Adiabatic condition; air- & Condenser & $\Delta T_{\text {min }}=3 \mathrm{~K}$ \\
Combustion chamber & fuel ratio $=1$ (high gas & Pump & $\eta_{\text {is }}=0.95 ; \eta_{\text {mech }}=1$ \\
& temperature) & Turbine & $\eta_{\text {is }}=0.97 ; \eta_{\text {mech }}=1$ \\
\hline
\end{tabular}

Table 3. Assumptions for theoretical operating conditions of plant components

\begin{tabular}{llll}
\hline Component & Unavoidable conditions & Component & Unavoidable conditions \\
\hline Solar field & $\begin{array}{l}\eta O P T=1 ; \eta_{C L N}=1 ; \eta_{E N D} \\
\end{array}$ & Furnace heater & $\Delta T_{\min }=0 \mathrm{~K}$ \\
Hot tank & Perfect insulation & ORC preheater & $\Delta T_{\min }=0 \mathrm{~K}$ \\
Cold tank & Perfect insulation & Evaporator & $\Delta T_{\min }=0 \mathrm{~K}$ \\
\hline Air preheater & $\Delta T_{\min }=0 \mathrm{~K}$ & Recuperator & effectiveness $=1$ \\
Combustion chamber & $\begin{array}{l}\text { Adiabatic condition; real } \\
\text { mass flow rate and air- }\end{array}$ & Condenser & $\Delta T_{\text {min }}=0 \mathrm{~K}$ \\
& $\begin{array}{l}\text { Pump } \\
\text { fuel ratio; isolation of }\end{array}$ & & $\eta_{i s}=1 ; \eta_{\text {mech }}=1$ \\
& $\begin{array}{l}\text { combustion chemical } \\
\text { reaction from heat }\end{array}$ & Turbine & $\eta_{\text {is }}=1 ; \eta_{\text {mech }}=1$ \\
& transfer processes [37] & & \\
\hline
\end{tabular}

\subsubsection{Advanced exergy performance parameters}

The efficiency of system component $j$ under the advanced exergy analysis translates to the avoidable endogenous part, which indicates the real component performance with reference to the avoidable losses due to its internal operations, given as [37]:

$$
\varepsilon_{j}^{a}=\frac{\dot{E}_{o, j}}{\dot{E}_{i, j}-\dot{I}_{j}^{U N}-\dot{I}_{j}^{a v, e x}}
$$

Also, relative avoidable irreversibility $(R I)$ was obtained for each system component, based on the following:

$$
R I_{j}=\frac{\dot{I}_{j}^{a v}}{\sum_{j=1}^{n} \dot{I}_{j}^{a v}}
$$

where $n$ is the number of components in the system.

\subsection{Advanced exergoeconomic analysis}

Similar to the advanced exergy analysis, advanced exergoeconomic analysis of energy systems entails prior analysis based on conventional exergoeconomic approach. Conventional exergoeconomic analysis combines exergy-analysis and cost-analysis principles to provide practical insights into the costs of useful and destroyed exergy in each system component. A number of approaches have been formulated for doing this, but the popular Specific Exergy Costing (SPECO) 
approach is adopted in this study [13]. It entails definition of cost rate balance equations for each component of the system, as follows:

$$
\sum c \dot{E}_{i}+c_{q} \dot{E}_{q}+\dot{Z}=\sum c \dot{E}_{o}+c_{w} \dot{W}
$$

where $c$ is the cost per unit exergy of a stream, $\dot{E}$ the stream exergy rate, $\dot{E}_{q}$ the exergy rate due to heat transfer with a component, $c_{q}$ and $c_{w}$ the cost per unit exergy of heat and work exchange with a component, respectively, and $\dot{Z}$ the cost rate due to investment, operation and maintenance of a component, calculated as:

$$
\dot{Z}=Z \cdot \frac{1}{H_{A}} \cdot \frac{i n t(1+i n t)^{N}}{(1+i n t)^{N}-1} \cdot(1+M F)
$$

where $Z$ is the component purchasing cost, $H_{A}$ the annual equivalent hours of operation of the plant (assumed equal to 6000 hours in this study), $M F$ the maintenance factor (taken as $6 \%$ ), int the interest rate (taken conservatively as $7 \%$ here) and $N$ the plant life time (assumed equal to 25 years). Also, the cost rate of irreversibility $\left(\dot{C}_{I}\right)$, which is an economic loss to the system, is given as:

$$
\dot{C}_{I}=c_{f} \cdot \dot{I}
$$

where $c_{f}$ is the ratio of cost rate of fuel to fuel exergy, $€ / \mathrm{kWh}$. Comprehensive analysis provided by Turton, Bailie, Whiting, Shaeiwitz, and Bhattacharyya [47] was adopted for estimating $Z$ for ORC and biomass components, as elucidated in [48], assuming shell and tube configuration for heat exchangers and using effectiveness-NTU approach. Cost associated with engineering, procurement and construction (EPC) as well as taxes was factored into $Z$, at $11 \%$. The purchase costs of solar field and TES system are based on previous study [32]. The cost of Sardinian Eucalyptus was taken as $50 € /$ tonne in this study, which translates to $1.1 \mathrm{c} € / \mathrm{kWh}$ based on its energy contents.

In the advanced exergoeconomic analysis, $\dot{Z}$ and $\dot{C}_{I}$ are split into unavoidable, avoidable, endogenous and exogenous parts. In order to split $\dot{Z}$ into avoidable $\left(\dot{Z}^{a v}\right)$ and unavoidable $\left(\dot{Z}^{u n}\right)$ parts, exceedingly inefficient thermodynamic parameters were assumed for the respective components, under which the investment cost obtained for each component is unrealistically low [9]. The conditions adopted in this paper are reported in Table 4. This led to creation of other sets of hybrid systems, used for calculating unavoidable investment cost per unit of product exergy $\left(\dot{Z} / \dot{\mathrm{E}}_{o}\right)^{u n}$ for the respective components. Then, the unavoidable investment costs for the components under real conditions were calculated using:

$$
\dot{Z}^{u n}=\dot{E}_{o} \cdot\left(\dot{Z} / \dot{\mathrm{E}}_{o}\right)^{u n}
$$

For $\dot{C}_{I}$, the unavoidable parts were obtained as follows:

$$
\dot{C}_{I}^{u n}=c_{f}^{r} \cdot \dot{\mathrm{I}}^{\text {un }}
$$

Avoidable parts were obtained by subtracting unavoidable costs from the total costs in the respective components:

$$
\dot{Z}^{a v}=\dot{\mathrm{Z}}-\dot{Z}^{u n}
$$




$$
\dot{C}_{I}^{a v}=\dot{C}_{I}-\dot{C}_{I}^{u n}
$$

where $c_{f}^{r}$ is the cost of fuel obtained under real thermodynamic conditions of the respective components. Furthermore, $\dot{\mathrm{Z}}$ and $\dot{C}_{I}$ were split into endogenous $\left(\dot{Z}^{\text {en }}, \dot{C}_{I}^{\text {en }}\right)$ and exogenous $\left(\dot{Z}^{e x}, \dot{C}_{I}^{e x}\right)$ parts, as follows:

$$
\begin{gathered}
\dot{Z}^{e n}=\dot{\mathrm{E}}_{o}^{e n} \cdot\left(\dot{Z} / \dot{\mathrm{E}}_{o}\right)^{r} \\
\dot{C}_{I}^{e n}=c_{f}^{r} \cdot \dot{\mathrm{I}}^{e n} \\
\dot{Z}^{e x}=\dot{Z}-\dot{Z}^{e n} \\
\dot{C}_{I}^{e x}=\dot{C}_{I}-\dot{C}_{I}^{e n}
\end{gathered}
$$

where $\left(\dot{Z} / \dot{\mathrm{E}}_{o}\right)^{r}$ was obtained using the real thermodynamic parameters of the respective components. Similar to advanced exergy analysis procedures, the splitting options were combined, as follows:

$$
\begin{gathered}
\dot{Z}^{u n, e n}=\dot{\mathrm{E}}_{o}^{e n} \cdot\left(\dot{Z} / \dot{\mathrm{E}}_{o}\right)^{u n} \\
\dot{C}_{I}^{u n, e n}=c_{f}^{r} \cdot \dot{\mathrm{I}}^{u n, e n} \\
\dot{Z}^{u n, e x}=\dot{Z}^{u n}-\dot{Z}^{u n, e n} \\
\dot{C}_{I}^{u n, e x}=\dot{C}_{I}^{u n}-\dot{C}_{I}^{u n, e n} \\
\dot{Z}^{a v, e n}=\dot{Z}^{e n}-\dot{Z}^{u n, e n} \\
\dot{C}_{I}^{a v, e n}=\dot{C}_{I}^{e n}-\dot{C}_{I}^{u n, e n} \\
\dot{Z}^{a v, e x}=\dot{Z}^{e x}-\dot{Z}^{u n, e x} \\
\dot{C}_{I}^{a v, e x}=\dot{C}_{I}^{\text {ex }}-\dot{C}_{I}^{u n, e x}
\end{gathered}
$$

As can be seen from the equations highlighted above, successful application of advanced exergoeconomic analysis is centred on adequate estimation of unit exergy cost for each stream $(c)$ and cost of fuel for each component $\left(c_{f}^{r}\right)$. This requires formulation of auxiliary equations that would facilitate simultaneous solution of cost rate equations for all the system components (eq. 16). In SPECO approach, this is usually done by applying a set of rules, which basically assume that $c$ is the same at inlet and exit streams for the same working substance entering and leaving a 
component, regardless of the quality of energy content of the streams [49]. In addition to this traditional approach, a modified approach is incorporated in this study, which considers energy quality of each stream in formulating auxiliary cost equations. It involves adaptation of the energy level methodology developed in [50], which had been integrated into conventional exergoeconomic analysis [30]. In particular, the modified auxiliary costing approach is based on the assertion that unit exergy cost of each stream should be dirtectly proportional to the content and quality of its thermal energy that could be recovered. More specifically, for the same working substance entering a component from stream $i$ and leaving through stream $o$, the modified auxiliary costing principle is expressed as follows:

$$
\frac{c_{i}}{Y_{i}}=\frac{c_{o}}{Y_{o}}
$$

where $Y$ is the stream thermal energy level, defined as follows [50]:

$$
Y=1-T_{a}\left(\frac{d S}{d H}\right)=\left|1-\frac{T_{a}}{T}\right|
$$

where $d S$ and $d H$ are entropy change and enthalpy change, respectively. By applying this to all system components, new sets of auxiliary equations were obtained, resulting in markedly different values of $c$ and $c_{f}^{r}$ for the traditional and modified auxiliary costing approaches. Also, the unit cost of loss exergy of flue gas is set as zero under the modified auxiliary costing approach [49]. Table 5 reports the traditional and modified auxiliary costing equations obtained for all system components.

Suffice it to equally mention here that the modified cost formulation approach is applied to the advanced exergoeconomic methodology for the first time in this paper, to the best of authors' knowledge. When the results are compared with those of the traditional auxiliary costing approach, it would be possible to verify its necessity or otherwise for future incorporation into the widelyapplied exergoeconomic methodology.

Table 4 -Assumptions for unavoidable conditions for investment cost rates

\begin{tabular}{llll}
\hline Solar field & \multicolumn{1}{c}{$\dot{Z}^{U N}=0.98 \cdot \dot{\mathrm{Z}}$} & Furnace heater & $\Delta T_{\min }=80 \mathrm{~K}$ \\
Hot tank & $10 \%$ heat loss & ORC preheater & $\Delta T_{\min }=45 \mathrm{~K}$ \\
Cold tank & $8 \%$ heat loss & Evaporator & $\Delta T_{\min }=50 \mathrm{~K}$ \\
Air preheater & $\Delta T_{\min }=200 \mathrm{~K}$ & Recuperator & effectiveness $=0.70$ \\
& Ambient properties at & Condenser & $\Delta T_{\min }=20 \mathrm{~K}$ \\
Combustion chamber & inlet; Exit gas & Pump & $\eta_{i s}=0.70$ \\
& temperature $=750 \mathrm{~K}$ & Turbine & $\eta_{i s}=0.70$ \\
\hline
\end{tabular}

Table 5 - Cost rate balance and auxiliary equations for traditional and modified approaches

\begin{tabular}{cccc}
\hline Component (abbreviation) & Cost rate balance equation & $\begin{array}{c}\text { Auxiliary } \\
\text { equation } \\
\text { (traditional) }\end{array}$ & $\begin{array}{c}\text { Auxiliary } \\
\text { equation } \\
\text { (modified) }\end{array}$ \\
\hline Solar field (SF) & $\dot{C}_{1}+\dot{Z}_{S F}=\dot{C}_{2}$ & $c_{S}=0$ & \\
Hot tank (HT) & $\dot{C}_{2}+\dot{Z}_{H T}=\dot{C}_{4}$ & \\
Cold tank (CT) & $\dot{C}_{3}+\dot{Z}_{C T}=\dot{C}_{1}$ & \\
Air preheater (AP) & $\dot{C}_{22}+\dot{C}_{9}+\dot{Z}_{A P}=\dot{C}_{23}+\dot{C}_{7}$ & $c_{22}=0 ; c_{9}=c_{23}$ & $c_{22}=0 ; c_{23}=0$
\end{tabular}




\begin{tabular}{cccc} 
Combustion chamber (CC) & $\dot{C}_{7}+\dot{C}_{b}+\dot{Z}_{C C}=\dot{C}_{8}$ & $c_{b}=1.1 \frac{\mathrm{c} €}{\mathrm{kWh}}$ & $c_{b}=1.1 \frac{\mathrm{c} €}{\mathrm{kWh}}$ \\
Furnace heater (FH) & $\dot{C}_{8}+\dot{C}_{5}+\dot{Z}_{F H}=\dot{C}_{9}+\dot{C}_{6}$ & $c_{8}=c_{9}$ & $\frac{c_{8}}{Y_{8}}=\frac{c_{9}}{Y_{9}}$ \\
ORC preheater (PRHT) & $\dot{C}_{11}+\dot{C}_{18}+\dot{Z}_{P R H T}=\dot{C}_{19}+\dot{C}_{12}$ & $c_{11}=c_{12}$ & $\frac{c_{11}}{Y_{11}}=\frac{c_{12}}{Y_{12}}$ \\
Evaporator (EVAP) & $\dot{C}_{10}+\dot{C}_{19}+\dot{Z}_{E V A P}=\dot{C}_{11}+\dot{C}_{13}$ & $c_{10}=c_{11}$ & $\frac{c_{10}}{Y_{10}}=\frac{c_{11}}{Y_{11}}$ \\
Recuperator (RECP) & $\dot{C}_{14}+\dot{C}_{17}+\dot{Z}_{R E C P}=\dot{C}_{15}+\dot{C}_{18}$ & $c_{14}=c_{15}$ & $\frac{c_{14}}{Y_{14}}=\frac{c_{15}}{Y_{15}}$ \\
Condenser (COND) & $\dot{C}_{15}+\dot{C}_{20}+\dot{Z}_{C O N D}=\dot{C}_{16}+\dot{C}_{21}$ & $c_{20}=0 ; c_{15}=c_{16}$ & $c_{20}=0 ; \frac{c_{15}}{Y_{15}}=\frac{c_{16}}{Y_{16}}$ \\
Pump (PUMP) & $\dot{C}_{16}+\dot{C}_{w, p}+\dot{Z}_{P U M P}=\dot{C}_{17}$ & $c_{w, p}=c_{w, T}$ & $c_{w, p}=c_{w, T}$ \\
Turbine (TURB) & $\dot{C}_{13}+\dot{Z}_{T U R B}=\dot{C}_{w, T}+\dot{C}_{14}$ & $c_{13}=c_{14}$ & $\frac{c_{13}}{Y_{13}}=\frac{c_{14}}{Y_{14}}$ \\
Valve 1 (V1) & $\dot{C}_{4}+\dot{C}_{6}+\dot{Z}_{V 1}=\dot{C}_{10}$ & & \\
Valve 2 (V2) & $\dot{C}_{12}+\dot{Z}_{V 2}=\dot{C}_{3}+\dot{C}_{5}$ & $c_{12}=c_{3}=c_{5}$ & $c_{12}=c_{3}=c_{5}$ \\
\hline
\end{tabular}

\subsubsection{Advanced exergoeconomic performance parameters}

The performance of each component was assessed using $\dot{C}_{I}^{a v, e n}, \dot{Z}^{\text {av,en }}$ and the advanced exergoeconomic factor $\left(f^{a v, e n}\right)$, defined as follows [18]:

$$
f^{a v, e n}=\frac{\dot{Z}^{a v, e n}}{\dot{Z}^{a v, e n}+\dot{C}_{I}^{a v, e n}}
$$

Furthermore, by using the overall cost rates obtained under the conventional exergoeconomic analysis, exergoeconomic factor (eq. 45) is modified to obtain the equivalence for conventional analysis, thereby enabling comparison of results of conventional and advanced exergoeconomic analyses.

\section{Results and discussion}

Table 6 shows the real process data for each thermodynamic stream of the system, emanating from the design characteristics of different units of the plant and ensuring balanced mass and energy flow based on first and second laws of thermodynamics. 
Table 6 - Plant process data under nominal and real thermodynamic conditions

\begin{tabular}{lllll}
\hline Stream No & Working substance & Mass flow rate $(\mathrm{kg} / \mathrm{s})$ & Temperature $(\mathrm{K})$ & Pressure (bar) \\
\hline 1 & Thermal oil & 6.63 & 436.50 & 3 \\
2 & Thermal oil & 6.63 & 550.65 & 3 \\
3 & Thermal oil & 6.63 & 438.15 & 3 \\
4 & Thermal oil & 6.63 & 548.15 & 3 \\
5 & Thermal oil & 4.42 & 438.15 & 3 \\
6 & Thermal oil & 4.42 & 548.15 & 3 \\
7 & Air & 1.65 & 378.15 & 1 \\
8 & Combustion gases & 1.79 & 1079.00 & 1 \\
9 & Combustion gases & 1.79 & 488.15 & 1 \\
10 & Thermal oil & 11.05 & 548.15 & 3 \\
11 & Thermal oil & 11.05 & 446.24 & 3 \\
12 & Thermal oil & 11.05 & 438.15 & 3 \\
13 & $M M$ & 8.55 & 477.97 & 10 \\
14 & $M M$ & 8.55 & 420.67 & 0.12 \\
15 & $M M$ & 3.55 & 314.78 & 0.12 \\
16 & $M M$ & 8.55 & 314.78 & 0.12 \\
17 & $M M$ & 390.07 & 10 \\
18 & $M M$ & 400.07 & 10 \\
19 & $M M$ & 298.15 & 10 \\
20 & Water & 8.55 & 308.15 & 1 \\
21 & Water & 50.21 & 298.15 & 1 \\
22 & Air & 50.21 & 396.16 & 1 \\
23 & Combustion gases & 1.65 & & 1 \\
\hline
\end{tabular}

\subsection{Results of advanced exergy analysis}

For clearer illustration of the results of advanced exergoeconomic analysis which is the main goal in this paper, comprehensive results of advanced exergy analysis are first presented in this section. Table 7 reports, under real thermodynamic conditions for each system component, the fuel exergy $\left(\dot{E}_{i}^{r}\right)$, the product exergy $\left(\dot{E}_{o}^{r}\right)$, the total irreversibility $\left(\dot{I}^{r}\right)$, as well as the different proportions of irreversibility based on the aforementioned advanced splitting options. All the input exergy into a component that wouldn't yield useful output were considered as the component total irreversibility in this paper. As can be seen in Table 7, the total irreversibility was obtained to be much higher in the solar field and combustion chamber, obviously due to high losses to heat transfer processes in these components. Also, noticeably high irreversibility rates were recorded in most of the other heat exchangers (furnace heater, evaporator, condenser and recuperator), as well as in the turbine. Advanced splitting of these irreversibility rates into endogenous and exogenous parts enabled the understanding of their sources. For the solar field, results showed that irreversibility rates are exclusively endogenous, connoting that its interaction with other components has no significant impact on the losses. This is in order for the studied system, since huge part of the solar exergy is expected to be lost to radiation and reflection on impinging the solar collectors, as well as due to flow of HTF in the receiver. Moreover, it can be seen from Table 7 that higher fractions of total irreversibility rates are endogenous than exogenous in most of the components. This connotes that thermodynamic interdependencies of the system components are weak, and improvement efforts could be as well focused on the individual components. The components with considerable losses due to interactions with other system components are the air preheater, TES tanks, recuperator, combustion chamber and condenser, respectively with $61 \%, 36 \%, 28 \%, 26 \%$ and $19 \%$ of their irreversibility rates being exogenous. In order to reduce irreversibility rates in these components, efforts should be directed at optimizing the entire system as a whole. In particular, in the case of an existing operational plant typical of the hybrid solar-biomass ORC plant being investigated here, 
enhancement of the combustion process is essential through careful selection of the biomass fuel as well as air-fuel ratio required for complete combustion, amongst others. In addition, internal thermal energy recovery measures should be implemented in all thermodynamic points where such is possible. Conversely, for new systems of such kinds, design procedures should incorporate detailed multi-objective optimization processes using established and robust algorithms such as the elitist non-dominated sorting genetic algorithm (NSGA-II), particle swarm optimization, amongst others.

In addition, the results of avoidability of irreversibility in each component places high premium on practical optimization of the hybrid plant being studied, as more than $50 \%$ of total irreversibility rates can be avoided in all components, with the exception of furnace heater. In fact, the total optimization potential of the hybrid plant is obtained when all the avoidable irreversibility rates in all the components are summed. The relative avoidable irreversibility indices obtained for each of the components are shown in Figure 3, which places high importance on solar field, combustion chamber, evaporator and turbine. Thus, the results showing combination of the splitting options highlighted in Table 8 are essential, to further reveal impacts of component interdependencies on avoidable irreversibility rates. Some of the exogenous results are negative due to differences in mass flow rates of working substances in real and hybrid systems based on the assumed conditions. As it would be expected, the impacts of structural arrangement of components are marginally higher for the combined splitting options, since the determining ratio now excludes unavoidable irreversibility in the respective components. In particular, it can be deduced that the impacts of component interactions on avoidable irreversibility are most significant in air preheater, combustion chamber and TES, based on the values obtained for avoidable exothermic irreversibility. For other components and for the unavoidable irreversibility, the effects of component interactions are observed to be relatively insignificant, thereby corroborating the fact that optimizing the individual components would substantially improve thermodynamic performance of the entire system. Moreover, it is quite interesting to observe that a relatively low efficiency of furnace heater is obtained from the conventional analysis, with most of the irreversibilities being endogenous and unavoidable; and the efficiency obtained from the advanced analysis also highlights this fact.

Furthermore, Figure 4 shows that exergetic efficiencies obtained for almost all the system components are higher by reckoning only with the useful exergy inputs and avoidable irreversibilities as done in the advanced exergy analysis. This further justifies the importance of applying advanced exergy method to energy systems analyses, since it reveals real component productivities better than what obtains with the conventional method. 
Table 7 - Results of advanced exergy analysis - single splitting options

\begin{tabular}{llllllll}
\hline Component & $\dot{\boldsymbol{E}}_{\boldsymbol{i}}^{\boldsymbol{r}}(\mathbf{k W})$ & $\dot{\boldsymbol{E}}_{\boldsymbol{o}}^{\boldsymbol{r}}(\mathbf{k W})$ & $\dot{\boldsymbol{I}}^{\boldsymbol{r}}(\mathbf{k W})$ & $\dot{\boldsymbol{I}}^{\boldsymbol{u n}}(\boldsymbol{\%})$ & $\dot{\boldsymbol{I}}^{\boldsymbol{a} \boldsymbol{v}}(\boldsymbol{\%})$ & $\dot{\boldsymbol{I}}^{\boldsymbol{e n}}(\boldsymbol{\%})$ & $\dot{\boldsymbol{I}}^{\boldsymbol{e x}}(\boldsymbol{\%})$ \\
\hline Solar field & 3922.3 & 679.0 & 3243.3 & 16.0 & 84.0 & 100 & 0 \\
Hot tank & 989.8 & 971.0 & 18.8 & 0 & 100 & 63.8 & 36.2 \\
Cold tank & 317.7 & 310.8 & 7.0 & 0 & 100 & 64.3 & 35.7 \\
Air preheater & 63.7 & 21.1 & 42.6 & 0.9 & 99.1 & 39.2 & 60.8 \\
Combustion & 2301.9 & 915.8 & 1119.6 & 21.5 & 78.5 & 73.8 & 26.2 \\
chamber & & & & & & & \\
Furnace heater & 759.4 & 435.7 & 323.7 & 87.5 & 12.5 & 95.9 & 4.1 \\
ORC preheater & 60.6 & 45.7 & 15.0 & 4.4 & 95.5 & 92.0 & 8.0 \\
Evaporator & 1028.3 & 880.0 & 148.3 & 11.9 & 88.1 & 90.3 & 9.7 \\
Recuperator & 268.9 & 200.9 & 68.0 & 45.0 & 54.9 & 72.2 & 27.7 \\
Condenser & 122.7 & 34.4 & 88.3 & 22.5 & 77.5 & 80.6 & 19.4 \\
Pump & 14.5 & 11.5 & 3.0 & 20.0 & 80.0 & 80.0 & 20.0 \\
Turbine & 746.5 & 643.7 & 102.8 & 13.7 & 86.3 & 100 & 0 \\
\hline
\end{tabular}

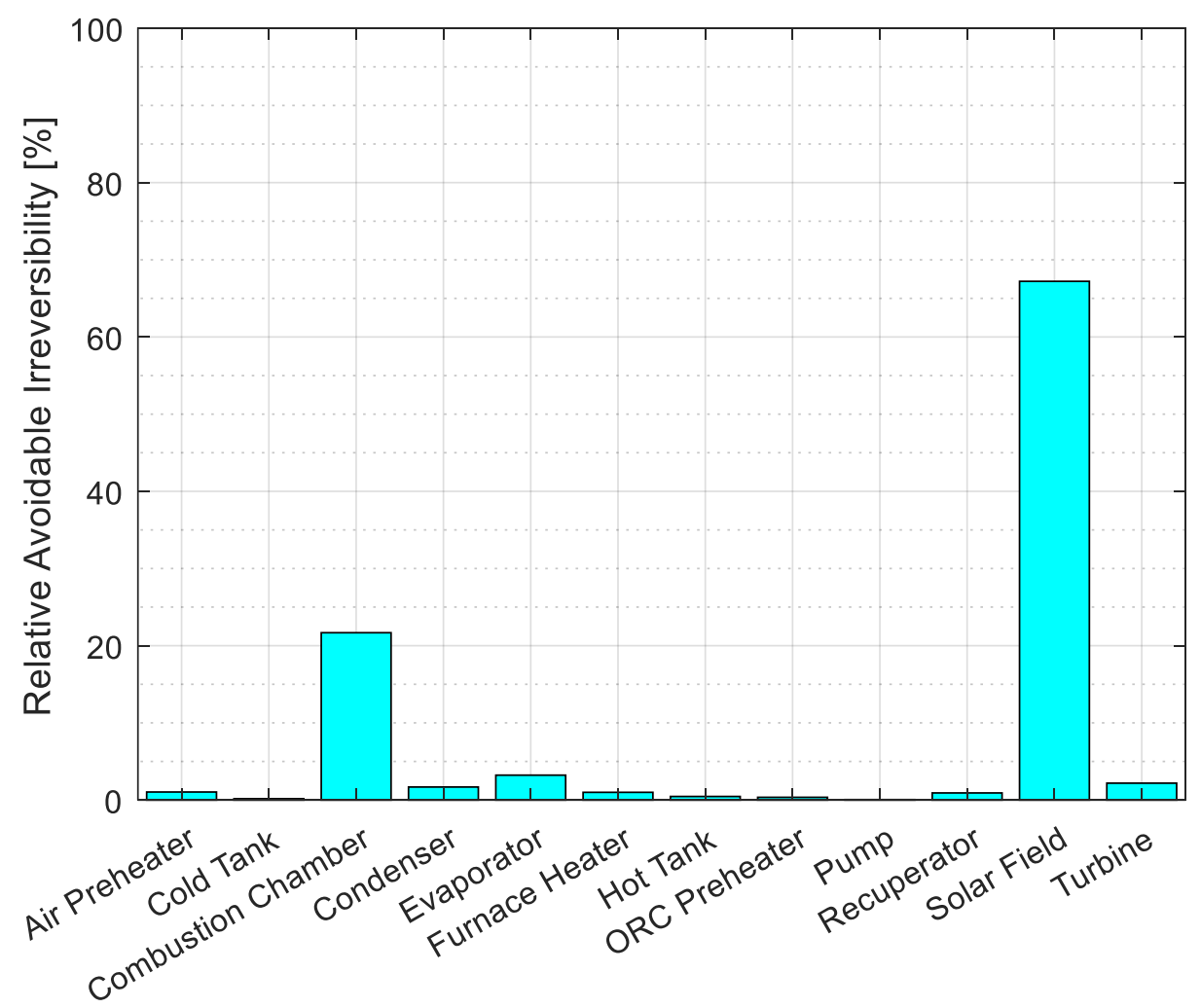

Figure 3 - Relative avoidable irreversibility in different components of the hybrid plant 
Table 8 - Results of advanced exergy analysis - combined splitting options

\begin{tabular}{lllll}
\hline Component & $\begin{array}{l}\dot{I}^{\text {av,en }} \\
(\mathbf{k W})\end{array}$ & $\begin{array}{l}\dot{I}^{\text {av,ex }} \\
(\mathbf{k W})\end{array}$ & $\begin{array}{l}\dot{\boldsymbol{I}}^{\text {un,en }} \\
(\mathbf{k W})\end{array}$ & $\begin{array}{l}\dot{\boldsymbol{I}}^{\text {un,ex }} \\
(\mathbf{k W})\end{array}$ \\
\hline Solar field & 2725.3 & -0.6 & 518.0 & 0.6 \\
Hot tank & 12.0 & 6.8 & 0 & 0 \\
Cold tank & 4.5 & 2.5 & 0 & 0 \\
Air preheater & 16.6 & 25.5 & 0.1 & 0.3 \\
Combustion & 622.4 & 256.4 & 203.5 & 37.2 \\
chamber & & -12.1 & 257.9 & 25.3 \\
Furnace heater & 52.6 & 1.0 & 0.5 & 0.1 \\
ORC preheater & 13.3 & 11.6 & 14.8 & 2.8 \\
Evaporator & 119.2 & 10.0 & 21.8 & 8.8 \\
Recuperator & 27.3 & 13.4 & 16.1 & 3.8 \\
Condenser & 55.0 & 0.5 & 0.5 & 0.1 \\
Pump & 2.0 & 0 & 14.1 & 0 \\
Turbine & 88.7 & &
\end{tabular}
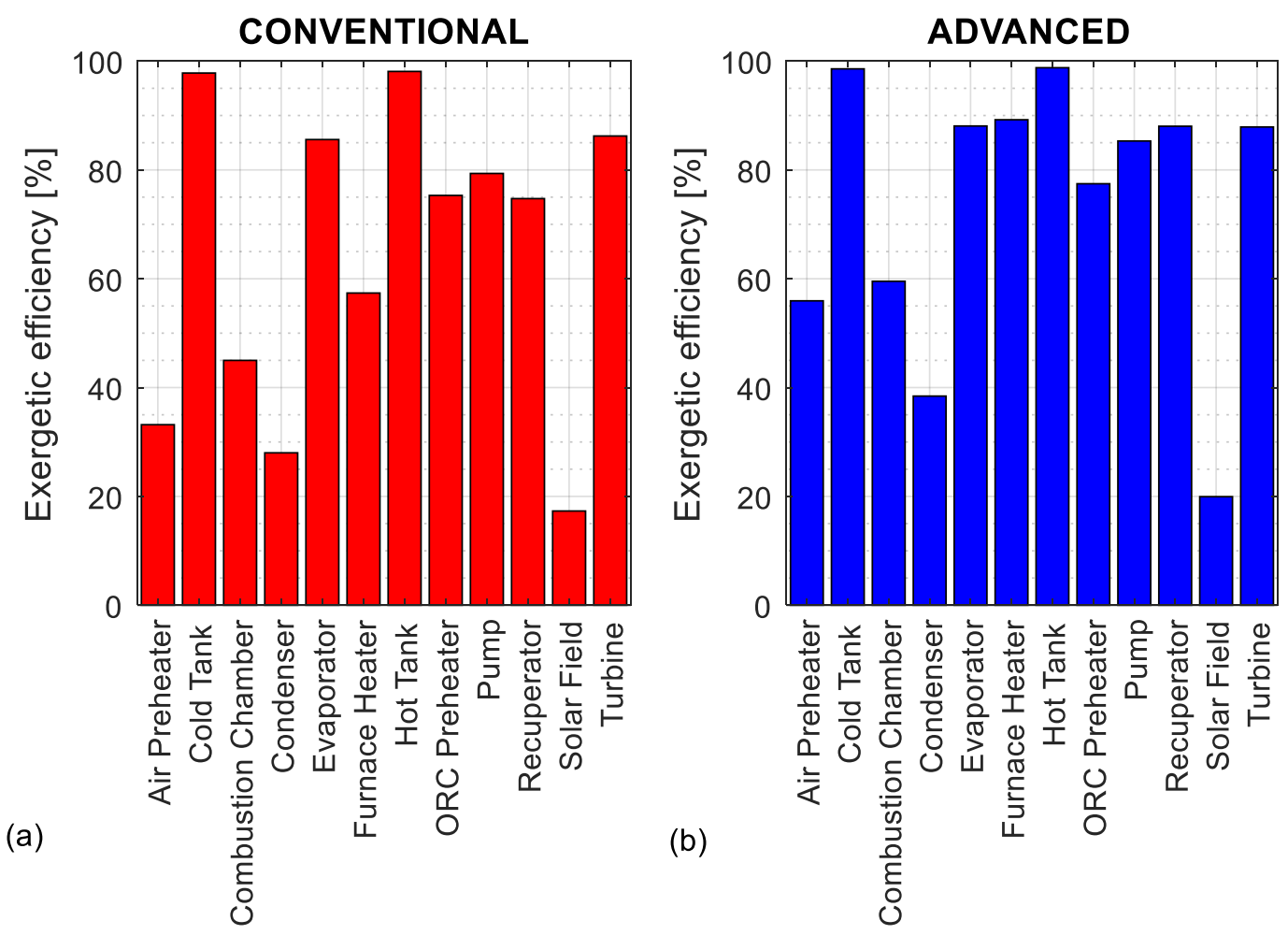

Figure 4 - Comparison of conventional and advanced exergetic efficiencies for the hybrid plant

\subsection{Results of advanced exergoeconomic analysis}

\subsubsection{Analysis based on splitting of the investment cost rates}

The levelized cost rates due to investment, operation and maintenance $(\dot{Z})$ and their segregates based on the splitting options of advanced exergoeconomic analysis are presented in Table 9. Here too, it can be seen that the impacts of interactions amongst the system components on investment cost rates are quite weak, with most of the cost rates being endogenous. In particular, the exogenous investment cost rate is less than $36 \%$ of the total investment cost rates in all components, with the 
exception of air preheater where it is about $86 \%$. What this implies is that the overall investment cost rates of the hybrid plant could be substantially optimized by singly improving capital costs associated with the individual components. An exemplary approach to this is by considering cheaper materials and manufacturing processes that would not compromise the level of thermodynamic performance of the individual components. However, results equally showed that large parts of the endogenous investment cost rates are unavoidable. Thus, the real potentials of economic improvements based on the investment cost rates are better ranked using the avoidable endogenous parts of the investment cost rates $\left(\dot{\boldsymbol{Z}}^{a v, e n}\right)$. In this regard, efforts should be placed on the system components in the following descending order: combustion chamber, recuperator, evaporator, solar field, furnace heater, turbine, cold tank, ORC preheater, hot tank, condenser, pump and air preheater. Suffice it to emphasise here that this ranking focuses only on the potentiality of improving just the investment cost rates, and the cost rates due to irreversibility should also be considered for a definitive analysis.

Table 9 - Results of advanced exergoeconomic analysis - investment cost rates

\begin{tabular}{|c|c|c|c|c|c|c|c|c|c|}
\hline Component & $\dot{\mathbf{Z}}^{r}(€ / \mathrm{h})$ & $\dot{\mathbf{Z}}^{u n}(\%)$ & $\begin{array}{l}\dot{\boldsymbol{Z}}^{a v} \\
(\%)\end{array}$ & $\begin{array}{l}\dot{\mathbf{Z}}^{e n} \\
(\%)\end{array}$ & $\dot{\mathbf{Z}}^{e x}(\%)$ & $\begin{array}{l}\dot{\boldsymbol{Z}}^{a v, e n} \\
(\%)\end{array}$ & $\begin{array}{l}\dot{Z}^{a v, e x} \\
(\%)\end{array}$ & $\begin{array}{l}\dot{\mathbf{Z}}^{u n, e n} \\
(\%)\end{array}$ & $\begin{array}{l}\dot{Z}^{u n, e x} \\
(\%)\end{array}$ \\
\hline Solar field & 22.62 & 98.0 & 2.0 & 99.9 & 0.1 & 2.0 & 0 & 97.9 & 0.1 \\
\hline Hot tank & 5.76 & 95.9 & 4.0 & 63.8 & 36.2 & 2.6 & 1.4 & 61.3 & 34.7 \\
\hline Cold tank & 5.76 & 94.0 & 6.0 & 64.5 & 35.2 & 3.8 & 2.1 & 60.8 & 33.2 \\
\hline Air preheater & 0.87 & 80.5 & 19.5 & 13.8 & 86.2 & 2.3 & 17.2 & 11.5 & 69.0 \\
\hline $\begin{array}{l}\text { Combustion } \\
\text { chamber }\end{array}$ & 2.14 & 46.3 & 53.7 & 84.6 & 15.4 & 45.3 & 8.4 & 39.3 & 7.0 \\
\hline Furnace heater & 1.69 & 79.9 & 20.1 & 91.1 & 8.9 & 18.3 & 1.8 & 72.8 & 7.1 \\
\hline ORC preheater & 2.03 & 86.2 & 13.8 & 76.8 & 23.2 & 10.3 & 3.5 & 66.5 & 19.7 \\
\hline Evaporator & 5.06 & 82.6 & 17.4 & 84.0 & 16.0 & 14.6 & 2.8 & 69.4 & 13.2 \\
\hline Recuperator & 4.89 & 76.1 & 23.9 & 71.3 & 28.7 & 17.0 & 6.9 & 54.2 & 21.9 \\
\hline Condenser & 2.88 & 94.9 & 5.0 & 80.9 & 19.1 & 4.2 & 1.0 & 76.7 & 18.1 \\
\hline Pump & 0.094 & 59.6 & 40.4 & 81.9 & 18.1 & 33.0 & 7.4 & 48.9 & 10.6 \\
\hline Turbine & 2.71 & 90.0 & 10.0 & 100 & 0 & 10.0 & 0 & 90.0 & 0 \\
\hline Valve 1 & 0 & 0 & 0 & 0 & 0 & 0 & 0 & 0 & 0 \\
\hline Valve 2 & 0 & 0 & 0 & 0 & 0 & 0 & 0 & 0 & 0 \\
\hline
\end{tabular}

\subsubsection{Analysis based on splitting of the irreversibility cost rates}

The impacts of system structures on irreversibility cost rates are analysed in this section, considering both the aforementioned traditional and modified auxiliary costing approaches. Beyond what is obtainable in conventional exergoeconomic analysis, advanced methodology reveals the parts of cost rates of irreversibility that could be avoided in all components, as well as the impacts of system structure on these cost rates. The comprehensive results are presented in Tables 10 and 11 for the traditional and modified costing approaches, respectively. As can be seen, large fractions of irreversibility cost rates are generally avoidable in all components (greater than $60 \%$, with the exception of furnace heater), irrespective of the auxiliary costing approach. Similarly, for the two auxiliary costing approaches, results showed that endogenous cost rates dominate in all system components, with the exception of air preheater. This connotes weak impacts of component interactions on economic losses due to irreversibility, which once again corroborates that each component should be optimized individually. Also, this suggests that the optimization potential in each component could be sufficiently ranked using just the avoidable endogenous part $\left(\dot{\boldsymbol{C}}_{I}^{a v, e n}\right)$, which are visible in Tables 10 and 11.

In addition, juxtaposing Tables 10 and 11 shows that different orders of avoidable endogenous irreversibility cost rates are obtained for the two auxiliary costing approaches. The same is shown more clearly in Figure 5, which compares avoidable irreversibility cost rates for the two auxiliary 
costing approaches. Apart from in solar field where $\dot{\boldsymbol{C}}_{I}^{a v, e n}$ is zero for both auxiliary costing approaches (due to zero cost of solar irradiation), results showed dissimilar variation trends in other components. Specifically, while $\dot{\boldsymbol{C}}_{I}^{a v, e n}$ increased in the modified approach relative to the traditional one for air preheater, combustion chamber, furnace heater, evaporator, recuperator, pump and turbine, it decreased in other system components. This indicates that how auxiliary exergy costing is defined in advanced exergoeconomic analysis plays significant roles on the results. For the two costing approaches considered in this study, the impacts on the main productive components of the hybrid cogeneration plant (turbine and condenser) are analysed. Figure 5 shows that, in the modified auxiliary costing approach relative to the traditional one, turbine $\dot{\boldsymbol{C}}_{I}^{a v \text {,en }}$ increased by about $17 \%$, while that of the condenser decreased by about $73 \%$. What this suggests is that the cost efficiency of electrical power production from the hybrid plant is slightly overestimated by the traditional auxiliary costing approach, while that of the co-production of heat is grossly underestimated. In reality based on several studies, cogeneration [51] and polygeneration [52] are known to improve techno-economic performance of energy systems, and not vice versa as suggested by applying the traditional auxiliary costing approach to the plant under investigation. This thus gives a sort of credibility and advantage to the modified auxiliary costing approach, and it should be adopted in future applications of advanced exergoeconomic methodology to energy system analyses. This is especially true when the system under investigation involves internal heat recovery for co-generation of products, as is the case in this paper.

Furthermore, the overall exergoeconomic ranking of components is obtained based on the sum of avoidable endogenous investment cost rates and avoidable endogenous irreversibility cost rates. Suffice it to mention again that the avoidable exogenous parts are basically excluded in these analyses due to the aforementioned general weak impacts of system structure on exergoeconomic performance. Thus, by considering Table 9 and Table 11 (for the modified costing approach), the decreasing order of importance of system components to improving exergoeconomic performance of the hybrid plant is: turbine, combustion chamber, evaporator, recuperator, furnace heater, condenser, ORC preheater, air preheater, hot tank, solar field, cold tank and pump. Also, exergoeconomic factor indicates the role of investment cost on exergoeconomic performance of a component, thereby placing importance on reduction of the investment cost or improvement of its thermodynamic performance. Figure 6 compares exergoeconomic factors for conventional and advanced exergoeconomic analyses, as well as for the two auxiliary exergy costing approaches considered in the advanced analysis. As can be seen, the effects of investment costs in exergoeconomic performance of almost all components are weakened in the advanced analysis, irrespective of the costing approach. This is because advanced analysis centres on avoidable cost rates, and it shows that the effects of thermodynamic inefficiencies of system components on economic underperformance are significantly higher than what obtains under the conventional method. Moreover, the effect of auxiliary costing approach on exergoeconomic factor is barely significant, obviously due to the same investment cost rate. 
Table 10 - Results of advanced exergoeconomic analysis - irreversibility cost rates based on traditional unit exergy costing

\begin{tabular}{|c|c|c|c|c|c|c|c|c|c|}
\hline Component & $\dot{\boldsymbol{C}}_{I}^{r}(€ / \mathrm{h})$ & $\dot{\boldsymbol{C}}_{I}^{u n}(€ / \mathrm{h})$ & $\begin{array}{l}\dot{\boldsymbol{C}}_{I}^{a v} \\
(€ / \mathrm{h})\end{array}$ & $\begin{array}{l}\dot{\boldsymbol{C}}_{I}^{e n} \\
(€ / \mathrm{h})\end{array}$ & $\begin{array}{l}\dot{\boldsymbol{C}}_{I}^{e x} \\
(€ / \mathrm{h})\end{array}$ & $\begin{array}{l}\dot{C}_{I}^{a v, e n} \\
(€ / \mathrm{h})\end{array}$ & $\begin{array}{l}\dot{C}_{I}^{a v, e x} \\
(€ / \mathrm{h})\end{array}$ & $\begin{array}{l}\dot{C}_{I}^{u n, e n} \\
(€ / h)\end{array}$ & $\begin{array}{l}\dot{\boldsymbol{C}}_{I}^{u n, e x} \\
(€ / \mathrm{h})\end{array}$ \\
\hline Solar field & 0 & 0 & 0 & 0 & 0 & 0 & 0 & 0 & 0 \\
\hline Hot tank & 0.86 & 0 & 0.86 & 0.55 & 0.31 & 0.55 & 0.31 & 0 & 0 \\
\hline Cold tank & 0.37 & 0 & 0.37 & 0.24 & 0.13 & 0.24 & 0.13 & 0 & 0 \\
\hline Air preheater & 1.26 & 0.01 & 1.25 & 0.49 & 0.76 & 0.49 & 0.75 & 0 & 0.01 \\
\hline $\begin{array}{l}\text { Combustion } \\
\text { chamber }\end{array}$ & 13.70 & 2.95 & 10.76 & 10.11 & 3.59 & 7.62 & 3.14 & 2.49 & 0.46 \\
\hline Furnace heater & 9.56 & 8.36 & 1.20 & 9.17 & 0.39 & 1.55 & -0.36 & 7.62 & 0.75 \\
\hline ORC preheater & 0.80 & 0.03 & 0.77 & 0.74 & 0.06 & 0.71 & 0.06 & 0.03 & 0 \\
\hline Evaporator & 7.93 & 0.94 & 6.99 & 7.16 & 0.77 & 6.37 & 0.62 & 0.79 & 0.15 \\
\hline Recuperator & 5.61 & 2.53 & 3.08 & 4.06 & 1.55 & 2.26 & 0.83 & 1.80 & 0.73 \\
\hline Condenser & 7.29 & 1.65 & 5.65 & 5.88 & 1.42 & 4.54 & 1.10 & 1.33 & 0.31 \\
\hline Pump & 0.30 & 0.06 & 0.24 & 0.24 & 0.06 & 0.20 & 0.05 & 0.05 & 0.01 \\
\hline Turbine & 8.49 & 1.16 & 7.32 & 8.49 & 0 & 7.32 & 0 & 1.16 & 0 \\
\hline Valve 1 & 0 & 0 & 0 & 0 & 0 & 0 & 0 & 0 & 0 \\
\hline Valve 2 & 0 & 0 & 0 & 0 & 0 & 0 & 0 & 0 & 0 \\
\hline
\end{tabular}

Table 11 - Results of advanced exergoeconomic analysis - irreversibility cost rates based on modified unit exergy costing

\begin{tabular}{llllllllll}
\hline Component & $\dot{\boldsymbol{C}}_{I}^{r}(€ / \mathrm{h})$ & $\dot{\boldsymbol{C}}_{I}^{u n}(€ / \mathrm{h})$ & $\begin{array}{l}\dot{\boldsymbol{C}}_{I}^{a v} \\
(€ / \mathrm{h})\end{array}$ & $\begin{array}{l}\dot{\boldsymbol{C}}_{I}^{e n} \\
(€ / \mathrm{h})\end{array}$ & $\begin{array}{l}\dot{\boldsymbol{C}}_{I}^{e x} \\
(€ / \mathrm{h})\end{array}$ & $\begin{array}{l}\dot{\boldsymbol{C}}_{I}^{a v, e n} \\
(€ / \mathrm{h})\end{array}$ & $\begin{array}{l}\dot{\boldsymbol{C}}_{I}^{a v, e x} \\
(€ / \mathrm{h})\end{array}$ & $\begin{array}{l}\dot{\boldsymbol{C}}_{I}^{u n, e n} \\
(€ / \mathrm{h})\end{array}$ & $\begin{array}{l}\dot{\boldsymbol{C}}_{I}^{u n, e x} \\
(€ / \mathrm{h})\end{array}$ \\
\hline Solar field & 0 & 0 & 0 & 0 & 0 & 0 & 0 & 0 & 0 \\
Hot tank & 0.75 & 0 & 0.74 & 0.48 & 0.27 & 0.48 & 0.27 & 0 & 0 \\
Cold tank & 0.24 & 0 & 0.24 & 0.15 & 0.08 & 0.15 & 0.08 & 0 & 0 \\
Air preheater & 1.70 & 0.02 & 1.69 & 0.67 & 1.03 & 0.67 & 1.02 & 0 & 0.01 \\
Combustion & 14.07 & 3.02 & 11.04 & 10.38 & 3.69 & 7.82 & 3.22 & 2.56 & 0.47 \\
chamber & 10.73 & 9.38 & 1.34 & 10.29 & 0.44 & 1.74 & -0.40 & 8.55 & 0.84 \\
Furnace heater & 10.73 & 0.03 & 0.68 & 0.65 & 0.06 & 0.63 & 0.05 & 0.02 & 0.01 \\
ORC preheater & 0.71 & 0.99 & 7.39 & 7.57 & 0.81 & 6.74 & 0.65 & 0.84 & 0.16 \\
Evaporator & 8.38 & 2.70 & 3.29 & 4.32 & 1.66 & 2.41 & 0.88 & 1.92 & 0.77 \\
Recuperator & 5.98 & 0.45 & 1.54 & 1.60 & 0.38 & 1.23 & 0.30 & 0.36 & 0.09 \\
Condenser & 1.98 & 0.07 & 0.28 & 0.28 & 0.06 & 0.23 & 0.05 & 0.05 & 0.01 \\
Pump & 0.35 & 0.03 & 0.55 & 0 & 1.36 & 0 \\
Turbine & 9.91 & 1.36 & 8.55 & 9.91 & 0 & 8.55 & 0 \\
Valve 1 & 0 & 0 & 0 & 0 & 0 & 0 & 0 & 0 & 0 \\
Valve 2 & 0 & 0 & 0 & 0 & 0 & 0 & 0 & 0 & 0 \\
\hline
\end{tabular}




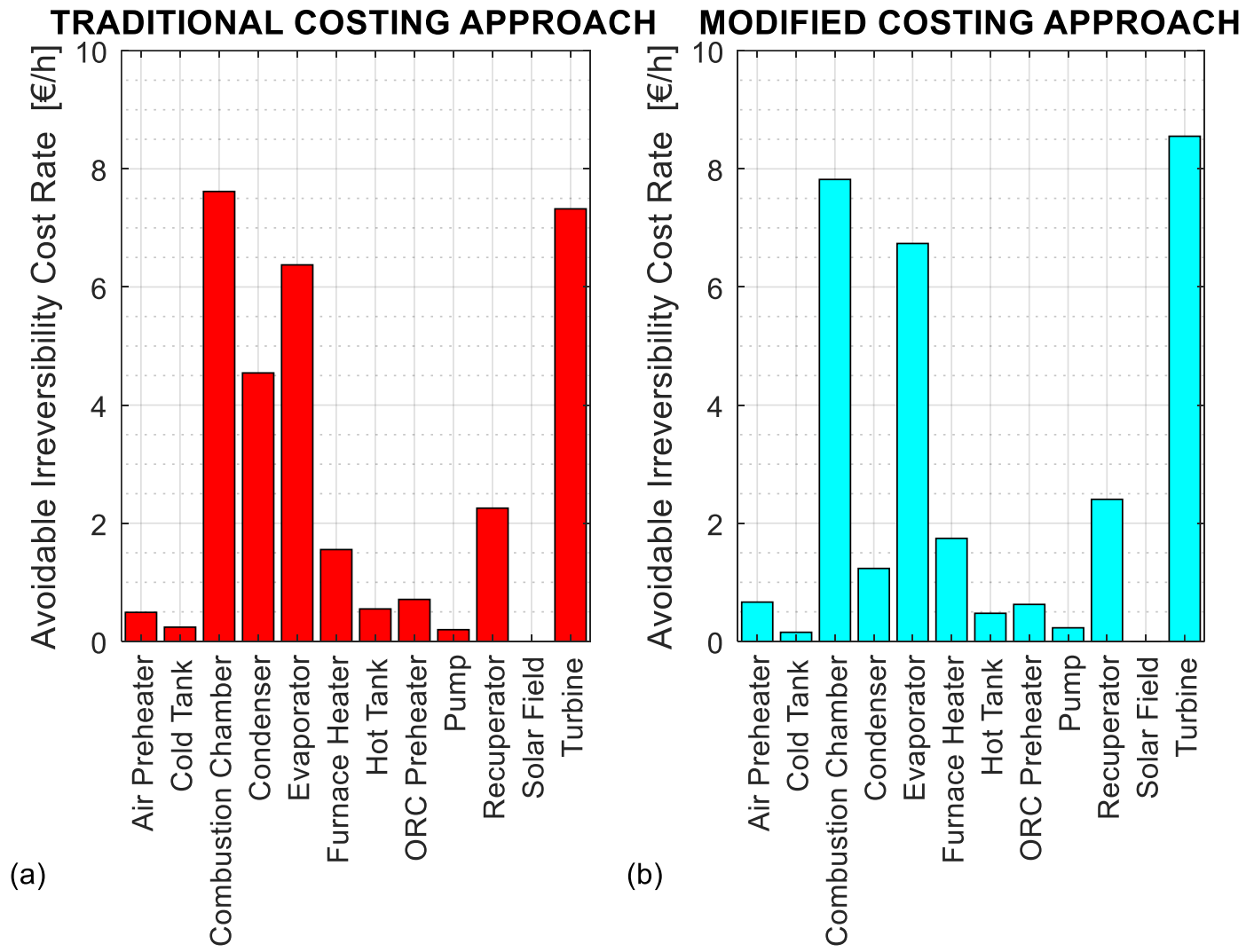

Figure 5 - Avoidable endothermic cost rate of irreversibility in each component for the traditional and modified auxiliary costing approaches
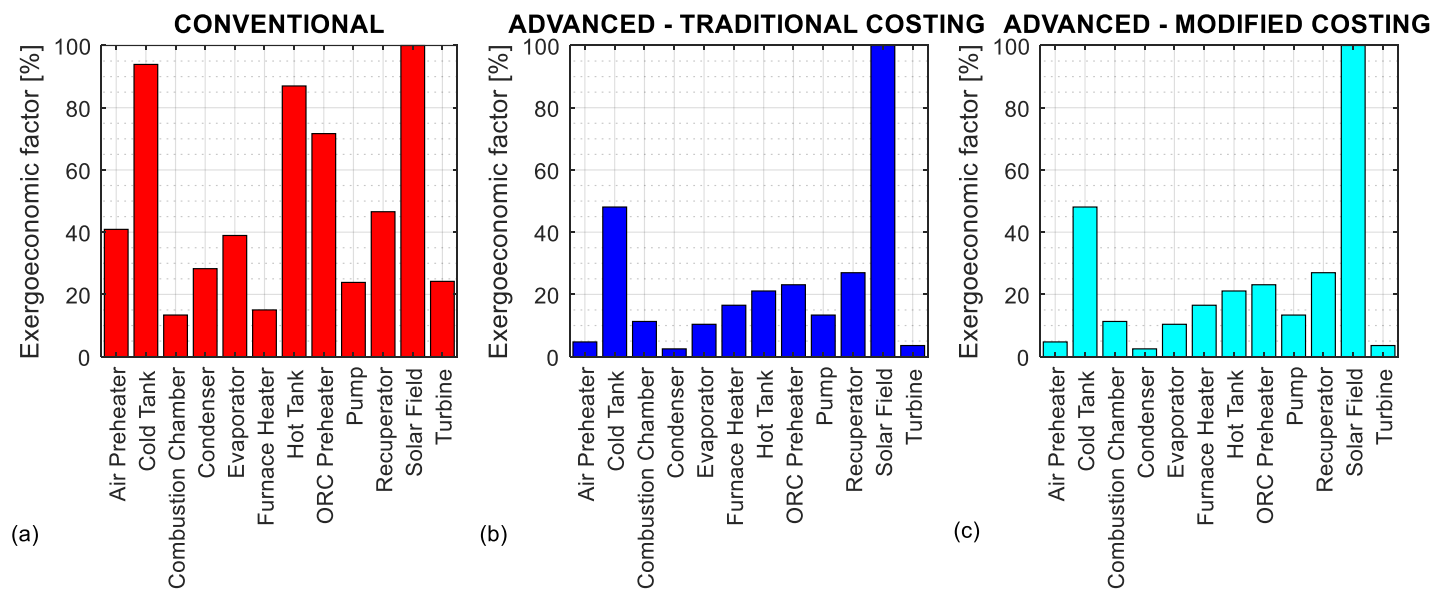

Figure 6 - Comparison of conventional and advanced exergoeconomic factors for the hybrid solarbiomass plant

\section{Conclusions}

Advanced exergoeconomic method has been applied in this study, to investigate improvement potentials in a hybrid solar-biomass ORC cogeneration plant. The hybrid plant had been earlier conceived as a structural optimization scheme to retrofit a real solar-ORC plant, which currently runs in Ottana, Italy. The main contribution of this paper centers on modification of the auxiliary exergy costing approach in the advanced exergoeconomic methodology, to reflect impacts of stream energy quality in the analysis. In addition, application of this method to solar-based systems is not as common in the state of the art. The main study findings are:

- More than $50 \%$ of total irreversibility rates can be avoided in almost all of the system components, suggesting that optimization of the plant is highly essential. Also, total 
irreversibility rates were obtained to be more endogenous than exogenous in most of the components, indicating weak thermodynamic interdependencies of the system components and that improvement efforts should be focused on internal operations of the individual components.

- The exogenous investment cost rate is less than $36 \%$ of the total investment cost rates in most of the components, implying weak impacts of component interactions on cost rates. However, results equally showed that large parts of the endogenous investment cost rates are unavoidable. Moreover, irreversibility cost rates larger than $60 \%$ were obtained to be avoidable in almost all components, irrespective of the auxiliary costing approach.

- It was obtained that how auxiliary exergy costing is defined in advanced exergoeconomic analysis plays significant roles on the results. In particular for the hybrid plant under study, about $17 \%$ increase in turbine avoidable endogenous irreversibility cost rate and about $73 \%$ decrease in that of condenser were observed in the modified auxiliary costing approach, relative to the traditional approach. By comparison with the impact that cogeneration of products is expected to have on system performance based on previous studies, it could be inferred that the modified auxiliary costing approach gives more practical results.

\section{Nomenclature}

\section{Letter symbols:}

\begin{tabular}{ll} 
& A $\quad$ area $\left(\mathrm{m}^{2}\right)$ \\
$c$ & average unit cost $(€ / \mathrm{kWh})$ \\
$\dot{C}$ & exergy cost rate $(€ / \mathrm{h})$ \\
$d$ & diameter $(\mathrm{m})$ \\
$e$ & specific exergy $(\mathrm{kJ} / \mathrm{kg})$ \\
$\dot{E}$ & rate of exergy $(\mathrm{kW})$ \\
$\dot{E}$ & exergy of the sun $(\mathrm{kW})$ \\
$f$ & exergoeconomic factor \\
$h$ & specific enthalpy $(\mathrm{kJ} / \mathrm{kg})$ \\
$H$ & annual plant operation $(\mathrm{hours})$ \\
$\dot{I}$ & rate of irreversibility $(\mathrm{kW})$ \\
$i n t$ & interest rate \\
$k$ & thickness $(\mathrm{m})$ \\
$m m$ & molar mass \\
$\dot{m}$ & mass flow rate $(\mathrm{kg} / \mathrm{s})$ \\
$M F$ & maintenance factor \\
$N$ & plant lifetime $(\mathrm{years})$ \\
$\dot{q}$ & specific thermal power $\left(\mathrm{W} / \mathrm{m}^{2}\right)$ \\
$\dot{Q}$ & thermal power $(\mathrm{kW})$ \\
$R I$ & relative avoidableirreversibility \\
$T$ & temperature $\left({ }^{\circ} \mathrm{C}, \mathrm{K}\right)$ \\
$t$ & time $(\mathrm{s})$ \\
$U$ & overall heat transfer coeff. \\
$V$ & (W/m $\left.{ }^{2} \mathrm{~K}\right)$ \\
$\dot{W}$ & volume (m $\left.{ }^{3}\right)$ \\
$Y$ & electrical power $(\mathrm{kW})$ \\
& energy quality level \\
\hline &
\end{tabular}

$Z \quad$ investment cost $(€)$

$\dot{Z} \quad$ investment and operation cost rate $(€ / h)$

\section{Greek symbols}

$\Delta T$ pinch point temperature difference $(\mathrm{K})$

$$
\begin{array}{ll}
\varepsilon & \text { exergetic efficiency } \\
\eta & \text { efficiency } \\
\alpha & \text { air convection heat transfer } \\
& \text { coefficient }\left(\mathrm{W} / \mathrm{m}^{2} \mathrm{~K}\right) \\
\rho & \text { density }\left(\mathrm{kg} / \mathrm{m}^{3}\right)
\end{array}
$$

\section{Subscripts and superscripts}
a ambient
$A$ annual
av avoidable
ch chemical
CLN clean
$d$ design
en endogenous
ex exogenous
$f$ fuel
$i$ inlet/fuel
ins insulation
is isentropic
L loss
mech mechanical
min minimum
$o$ outlet/product 


\begin{tabular}{|c|c|}
\hline$O P T \quad$ optical & $s f \quad$ solar field \\
\hline$p \quad$ product & th thermal \\
\hline$p l$ pipe loss & un unavoidable \\
\hline$q$ heat & \\
\hline$r \quad$ real & \\
\hline
\end{tabular}

\section{Acknowledgement}

This study was carried out under the Cooperation Agreement with "Ente Acque Sardegna" (ENAS) for the realization of the project "Thermodynamic solar plant for the development of an electrical and thermal energy smart grid" funded by P.O.R FESR 2014-2020 - Action line 4.3.1 - Framework agreement PT_CRP "Su Suercone Ambiente Identitario".

The authors thank ENAS for providing operational data and information on the Ottana Solar Facility and for setting up the experimental ORC plant.

\section{References}

[1] A. Modi, F. Bühler, J.G. Andreasen, F. Haglind, A review of solar energy based heat and power generation systems, Renew. Sustain. Energy Rev. 67 (2017) 1047-1064. doi:10.1016/J.RSER.2016.09.075.

[2] World Energy Outlook 2018, OECD, 2018. doi:10.1787/weo-2018-en.

[3] A.M. Pantaleo, S.M. Camporeale, A. Sorrentino, A. Miliozzi, N. Shah, C.N. Markides, Hybrid solar-biomass combined Brayton/organic Rankine-cycle plants integrated with thermal storage: Techno-economic feasibility in selected Mediterranean areas, Renew. Energy. 147 (2020) 2913-2931. doi:10.1016/J.RENENE.2018.08.022.

[4] S. Pramanik, R.V. Ravikrishna, A review of concentrated solar power hybrid technologies, Appl. Therm. Eng. 127 (2017) 602-637. doi:10.1016/J.APPLTHERMALENG.2017.08.038.

[5] M. Jradi, S. Riffat, Modelling and testing of a hybrid solar-biomass ORC-based micro-CHP system, Int. J. Energy Res. 38 (2014) 1039-1052. doi:10.1002/er.3145.

[6] A.H. Abedin, M.A. Rosen, Assessment of a closed thermochemical energy storage using energy and exergy methods, Appl. Energy. 93 (2012) 18-23. doi:10.1016/J.APENERGY.2011.05.041.

[7] T. J. Kotas, The exergy method of thermal plant analysis, Butterworths, 1985.

[8] Z. Wang, W. Xiong, D.S.-K. Ting, R. Carriveau, Z. Wang, Conventional and advanced exergy analyses of an underwater compressed air energy storage system, Appl. Energy. 180 (2016) 810-822. doi:10.1016/J.APENERGY.2016.08.014.

[9] G. Tsatsaronis, M.H. Park, On avoidable and unavoidable exergy destructions and investment costs in thermal systems, Energy Convers. Manag. 43 (2002) 1259-1270. doi:10.1016/S0196-8904(02)00012-2.

[10] A. Gungor, Z. Erbay, A. Hepbasli, Exergoeconomic analyses of a gas engine driven heat pump drier and food drying process, Appl. Energy. 88 (2011) 2677-2684. doi:10.1016/J.APENERGY.2011.02.001.

[11] R. Leiva-Illanes, R. Escobar, J.M. Cardemil, D.-C. Alarcón-Padilla, J. Uche, A. Martínez, Exergy cost assessment of CSP driven multi-generation schemes: Integrating seawater desalination, refrigeration, and process heat plants, Energy Convers. Manag. 179 (2019) 249269. doi:10.1016/J.ENCONMAN.2018.10.050.

[12] P. Ahmadi, 1.8 Exergoeconomics, Compr. Energy Syst. (2018) 340-376. doi:10.1016/B978- 
0-12-809597-3.00107-3.

[13] A. Lazzaretto, G. Tsatsaronis, SPECO: A systematic and general methodology for calculating efficiencies and costs in thermal systems, Energy. 31 (2006) 1257-1289. doi:10.1016/j.energy.2005.03.011.

[14] A. Valero, S. Usón, C. Torres, A. Valero, A. Agudelo, J. Costa, Thermoeconomic tools for the analysis of eco-industrial parks, Energy. $62 \quad$ (2013) 62-72. doi:10.1016/J.ENERGY.2013.07.014.

[15] Y. Ma, T. Morozyuk, M. Liu, J. Yan, J. Liu, Optimal integration of recompression supercritical CO2 Brayton cycle with main compression intercooling in solar power tower system based on exergoeconomic approach, Appl. Energy. 242 (2019) 1134-1154. doi:10.1016/J.APENERGY.2019.03.155.

[16] A. Abusoglu, M. Kanoglu, Exergoeconomic analysis and optimization of combined heat and power production: A review, Renew. Sustain. Energy Rev. 13 (2009) 2295-2308. doi:10.1016/J.RSER.2009.05.004.

[17] G. Tsatsaronis, Recent developments in exergy analysis and exergoeconomics, Int. J. Exergy. 5 (2008) 489-499. doi:10.1504/IJEX.2008.020822.

[18] G. Tsatsaronis, T. Morosuk, A general exergy-based method for combining a cost analysis with an environmental impact analysis. Part I - Theoretical development, in: ASME Int. Mech. Eng. Congr. Expo. Proc., 2009: pp. 453-462. doi:10.1115/IMECE2008-67218.

[19] M. Mehrpooya, S.A. Mousavi, Advanced exergoeconomic assessment of a solar-driven Kalina cycle, Energy Convers. Manag. $178 \quad$ (2018) 78-91. doi:10.1016/J.ENCONMAN.2018.10.033.

[20] M. Yu, P. Cui, Y. Wang, Z. Liu, Z. Zhu, S. Yang, Advanced Exergy and Exergoeconomic Analysis of Cascade Absorption Refrigeration System Driven by Low-Grade Waste Heat, ACS Sustain. Chem. Eng. 7 (2019) 16843-16857. doi:10.1021/acssuschemeng.9b04396.

[21] Z. Liu, Z. Liu, X. Yang, H. Zhai, X. Yang, Advanced exergy and exergoeconomic analysis of a novel liquid carbon dioxide energy storage system, Energy Convers. Manag. 205 (2020) 112391. doi:10.1016/J.ENCONMAN.2019.112391.

[22] Y. Wang, Y. Liu, X. Liu, W. Zhang, P. Cui, M. Yu, Z. Liu, Z. Zhu, S. Yang, Advanced exergy and exergoeconomic analyses of a cascade absorption heat transformer for the recovery of low grade waste heat, Energy Convers. Manag. 205 (2020) 112392. doi:10.1016/J.ENCONMAN.2019.112392.

[23] H. Ansarinasab, M. Mehrpooya, A. Mohammadi, Advanced exergy and exergoeconomic analyses of a hydrogen liquefaction plant equipped with mixed refrigerant system, J. Clean. Prod. 144 (2017) 248-259. doi:10.1016/J.JCLEPRO.2017.01.014.

[24] S. Anvari, R. Khoshbakhti Saray, K. Bahlouli, Conventional and advanced exergetic and exergoeconomic analyses applied to a tri-generation cycle for heat, cold and power production, Energy. 91 (2015) 925-939. doi:10.1016/J.ENERGY.2015.08.108.

[25] B. Dai, K. Zhu, Y. Wang, Z. Sun, Z. Liu, Evaluation of organic Rankine cycle by using hydrocarbons as working fluids: Advanced exergy and advanced exergoeconomic analyses, Energy Convers. Manag. 197 (2019) 111876. doi:10.1016/J.ENCONMAN.2019.111876.

[26] A. Keçebaş, A. Hepbasli, Conventional and advanced exergoeconomic analyses of geothermal district heating systems, Energy Build. 69 (2014) 434-441. doi:10.1016/J.ENBUILD.2013.11.011.

[27] P. Keçebaş, H. Gökgedik, M.A. Alkan, A. Keçebaş, An economic comparison and evaluation of two geothermal district heating systems for advanced exergoeconomic analysis, Energy Convers. Manag. 84 (2014) 471-480. doi:10.1016/J.ENCONMAN.2014.04.068.

[28] G.D. Vučković, M.M. Stojiljković, M. V. Vukić, G.M. Stefanović, E.M. Dedeić, Advanced exergy analysis and exergoeconomic performance evaluation of thermal processes in an 
existing industrial plant, Energy Convers. Manag. 85 (2014) 655-662. doi:10.1016/J.ENCONMAN.2014.03.049.

[29] F.A. Boyaghchi, M. Sabaghian, Advanced exergy and exergoeconomic analyses of Kalina cycle integrated with parabolic-trough solar collectors, Sci. Iran. 23 (2016) 2247-2260. doi:10.24200/sci.2016.3954.

[30] Z. Wang, W. Han, N. Zhang, M. Liu, H. Jin, Exergy cost allocation method based on energy level (ECAEL) for a CCHP system, Energy. 134 (2017) 240-247. doi:10.1016/j.energy.2017.06.015.

[31] J. Oyekale, M. Petrollese, T. Vittorio, G. Cau, Conceptual design and preliminary analysis of a CSP-biomass organic Rankine cycle plant, in: 31st Int. Conf. Effic. Cost, Optim. Simul. Environ. Impact Energy Syst. ECOS 2018, Guimaraes; Port., 2018.

[32] J. Oyekale, F. Heberle, M. Petrollese, D. Brüggemann, G. Cau, Biomass retrofit for existing solar organic Rankine cycle power plants: Conceptual hybridization strategy and technoeconomic assessment, Energy Convers. Manag. 196 (2019) 831-845. doi:10.1016/j.enconman.2019.06.064.

[33] I. Dincer, M.A. Rosen, Exergy, Elsevier Ltd, 2013.

[34] R. Petela, Exergy of Heat Radiation, J. Heat Transfer. 86 (2012) 187. doi:10.1115/1.3687092.

[35] S. Kelly, G. Tsatsaronis, T. Morosuk, Advanced exergetic analysis: Approaches for splitting the exergy destruction into endogenous and exogenous parts, Energy. 34 (2009) 384-391. doi:10.1016/J.ENERGY.2008.12.007.

[36] J. Wang, Y. Yang, Energy, exergy and environmental analysis of a hybrid combined cooling heating and power system utilizing biomass and solar energy, Energy Convers. Manag. 124 (2016) 566-577. doi:10.1016/J.ENCONMAN.2016.07.059.

[37] G. Tsatsaronis, T. Morosuk, A general exergy-based method for combining a cost analysis with an environmental impact analysis. Part II - Application to a cogeneration system, in: ASME Int. Mech. Eng. Congr. Expo. Proc., 2009: pp. 463-469. doi:10.1115/IMECE200867219.

[38] G. Cau, D. Cocco, Comparison of medium-size concentrating solar power plants based on parabolic trough and linear Fresnel collectors, Energy Procedia. 45 (2014) 101-110. doi:10.1016/j.egypro.2014.01.012.

[39] A. Mortazavi, M. Ameri, Conventional and advanced exergy analysis of solar flat plate air collectors, Energy. 142 (2018) 277-288. doi:10.1016/j.energy.2017.10.035.

[40] J. Oyekale, M. Petrollese, G. Cau, Multi-objective thermo-economic optimization of biomass retrofit for an existing solar organic Rankine cycle power plant based on NSGA-II, Energy Reports. (2019). doi:10.1016/j.egyr.2019.10.032.

[41] P.K. Nag, Power plant engineering, Tata McGraw-Hill Publishing Company Ltd, 2008.

[42] M.E. Demir, I. Dincer, Development and analysis of a new integrated solar energy system with thermal storage for fresh water and power production, Int. J. Energy Res. 42 (2018) 2864-2874. doi:10.1002/er.3846.

[43] Meteonorm: Meteonorm Software, (n.d.). https://www.meteonorm.com/en/product/productpage/meteonorm-software (accessed October 24, 2018).

[44] F. Calise, C. Capuozzo, A. Carotenuto, L. Vanoli, Thermoeconomic analysis and off-design performance of an organic Rankine cycle powered by medium-temperature heat sources, Sol. Energy. 103 (2014) 595-609. doi:10.1016/j.solener.2013.09.031.

[45] I.H. Bell, J. Wronski, S. Quoilin, V. Lemort, Pure and pseudo-pure fluid thermophysical property evaluation and the open-source thermophysical property library coolprop, Ind. Eng. Chem. Res. 53 (2014) 2498-2508. doi:10.1021/ie4033999. 
[46] M. Thol, F.H. Dubberke, G. Rutkai, T. Windmann, A. Köster, R. Span, J. Vrabec, Fundamental equation of state correlation for hexamethyldisiloxane based on experimental and molecular simulation data, Fluid Phase Equilib. 418 (2016) 133-151. doi:10.1016/J.FLUID.2015.09.047.

[47] R. Turton, R.C. Bailie, W.B. Whiting, J.A. Shaeiwitz, D. Bhattacharyya, Analysis, Synthesis , and Design of Chemical Processes, fourth ed, Prentice Hall, Upper Saddle River, NJ (USA), 2012.

[48] F. Heberle, M. Hofer, N. Ürlings, H. Schröder, T. Anderlohr, D. Brüggemann, Technoeconomic analysis of a solar thermal retrofit for an air-cooled geothermal Organic Rankine Cycle power plant, Renew. Energy. 113 (2017) 494-502. doi:10.1016/j.renene.2017.06.031.

[49] A. Bejan, E. Mamut, eds., Thermodynamic Optimization of Complex Energy Systems, Kluwer Academic Publishers, 1999.

[50] X.Z. Jiang, X. Wang, L. Feng, D. Zheng, L. Shi, Adapted computational method of energy level and energy quality evolution for combined cooling, heating and power systems with energy storage units, Energy. 120 (2017) 209-216. doi:10.1016/j.energy.2016.12.124.

[51] N.M. Isa, C.W. Tan, A.H.M. Yatim, A comprehensive review of cogeneration system in a microgrid: A perspective from architecture and operating system, Renew. Sustain. Energy Rev. 81 (2018) 2236-2263. doi:10.1016/j.rser.2017.06.034.

[52] K. Jana, A. Ray, M.M. Majoumerd, M. Assadi, S. De, Polygeneration as a future sustainable energy solution - A comprehensive review, Appl. Energy. 202 (2017) 88-111. doi:10.1016/j.apenergy.2017.05.129. 